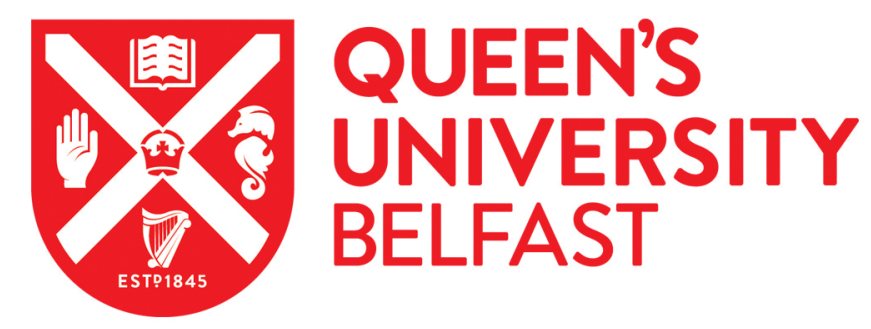

\title{
Boundary condition focused finite element model updating for bridges
}

Hester, D., Koo, K., Xu, Y., brownjohn, J., \& Bocian, M. (2019). Boundary condition focused finite element model updating for bridges. Engineering Structures. https://doi.org/10.1016/j.engstruct.2019.109514

\author{
Published in: \\ Engineering Structures
}

Document Version:

Peer reviewed version

Queen's University Belfast - Research Portal:

Link to publication record in Queen's University Belfast Research Portal

\section{Publisher rights}

Copyright 2019 Elsevier.

This manuscript is distributed under a Creative Commons Attribution-NonCommercial-NoDerivs License

(https://creativecommons.org/licenses/by-nc-nd/4.0/), which permits distribution and reproduction for non-commercial purposes, provided the author and source are cited.

\section{General rights}

Copyright for the publications made accessible via the Queen's University Belfast Research Portal is retained by the author(s) and / or other copyright owners and it is a condition of accessing these publications that users recognise and abide by the legal requirements associated with these rights.

Take down policy

The Research Portal is Queen's institutional repository that provides access to Queen's research output. Every effort has been made to ensure that content in the Research Portal does not infringe any person's rights, or applicable UK laws. If you discover content in the Research Portal that you believe breaches copyright or violates any law, please contact openaccess@qub.ac.uk. 

Updating for Bridges

\author{
Ki Koob ${ }^{b}$ David Hestera ${ }^{a}$ Yan Xud James Brownjohn ${ }^{b}$, Mateusz Bocianc, \\ aSchool of Natural and Built Environment, Queen's University Belfast, UK \\ ${ }^{b}$ Vibration Engineering Section, University of Exeter, UK \\ 'Department of Engineering, University of Leicester, UK \\ dJiangsu Key Laboratory of Engineering Mechanics, South East University, Nanjing, China
}

\section{Abstract}

This paper pays specific attention to measuring and identifying the behaviour of the bridge bearings of a short span highway bridge, as well as the static and dynamic data commonly used for model updating. This is important because while it is widely accepted that correct simulation of boundary conditions in a Finite Element (FE) model is crucial to the accuracy of the model, few researchers have actually attempted to measure bearing movement as part of their model updating strategy. To demonstrate the approach and the benefits of tracking bearing movement two separate updated FE models of the bridge were developed; (i) was updated using dynamic performance information, and (ii) was updated using response to quasi-static loading. The inclusion of bearing behaviour data proved to be very important, as in (i) it was found that during ambient vibration testing with low level dynamic response to light traffic, the friction on the bridge bearings was such that they were effectively behaving as 'pinned-pinned', as opposed to 'pinned-roller' as indicated by the bridge drawings. Using this observation it was possible to get the updated model (i) to match very closely with the experimentally measured frequencies and mode shapes. Without this information, conventional model updating optimisation would likely have driven the system parameters (e.g. Young's modulus, deck mass) to unrealistic values in order to get the FE predictions to match the experimentally observed frequencies. For the static model (ii) it was again observed that friction on the bearing was playing a significant role in the behaviour of the bridge and this was exploited to develop a simple but effective updated FE model that accurately predicted the bridge response during two separate static load tests. No single FE model could represent the bridge for both types of loading but in both cases the bearing performance data were critical in getting the relevant model to match the experimentally observed values.

\subsection{Introduction}

\subsection{Context of current study}

This paper focuses on the nuances of the behaviour of bridge bearings in service and the impacts this has on Finite Element Model Updating (hereafter referred to as FEMU). The next section 
describes in more detail the work to be undertaken. However, to give context to the current study this section gives a brief overview of some of the previous work carried out in this area.

Most of bridge FEMU studies have been based on operational modal frequencies and mode shapes from ambient vibration tests using accelerometers for various bridge types: suspension bridge [1], [2], cable-stayed bridge [3], [4], Pre Stressed Concretre (PSC) box-girder bridge [5], [6], and arch bridge [7], [8]. Accelerometers were widely used due to their ease of use in the field.

One problem of using modal parameters in FEMU was a limited number of data points, i.e. a few lower natural frequencies and corresponding mode shape amplitudes. The limited data points can lead to the ill-conditioning in the optimisation process, especially when many optimisation variables are used [9], [10]. In effect, the limited data points tends to lower the number of optimisation variables to avoid the ill-conditioning. The dynamically updated FE model based on modal parameters must be used carefully to predict static response as there is no guarantee of accuracy for static response prediction.

To overcome this problem and to bring more confidence in the updated model, static measurement quantities such as displacement, strain or tilt were used together with modal parameters [11]-[14]. However, the accuracies of the updated FE models achieved were not consistently high for either dynamic only updating or combined dynamic and static updating. The maximum absolute errors of modal frequencies ranged typically from $5 \%$ to $20 \%$, but in some instances were even higher [11], [15], [16]. This may be due to measurement noise, but one of the fundamental sources of this uncertainty is the FE modelling errors [12], [14], [17], [18]. This is because the common bridge bearings' modelling method, i.e. relying on using ideal rollers or hinges in FE models, is far from the actual friction behaviour. Also, composite action between the slab and the girders of a bridge may be uncertain in an operational condition [19].

Due to these known sources of error Goulet et al. [20] proposed the idea of generating multiple prototype models of the bridge using a probabilistic approach. Then following the results of some field testing, prototype models that are shown to give the correct predictions (within a certain range/threshold) are identified as candidate models. The approach was demonstrated using static load test data from an $80 \mathrm{~m}$ span concrete bridge. More recently the same authors have presented an evolution of the concept, specifically an error-domain structural identification approach that uses model falsification to identify candidate models [21], [22]. This is based on the concept that in science, data cannot truly validate a hypothesis therefore it can only be used falsify it. This approach has been used by Goulet et al to look at the effects of modelling simplification for structural identification of bridges [23], and the more general challenge of dealing with the systematic errors and unknown uncertainty dependencies that can occur in updated FE models [24]. In related work, Brynjarsdottir and O'Hagan [25] discuss how to deal with model discrepancy in Bayesian updating and its effect/limitation. 


\subsection{Overview of paper content}

The aim of this paper is to examine by way of a case study how monitoring bridge bearing movements can be helpful for Finite Element model updating. Historically, updated FE models have been used to predict both dynamic and static behaviour and hence the same approach is adopted in this paper. The paper has the following steps:

(i) a modal test on the bridge is undertaken where bearing movement is also monitored,

(ii) a finite element model of the bridge is prepared using the available drawings which we term Model 0

(iii) Model 0 is updated so that the mode shapes and frequencies from the model match those observed on site thereby giving an accurate 'dynamic model' which for convenience we term Model 1. In this step having information on the movement of the bearings proves crucial in developing the updated model as it was demonstrated that in ambient conditions with just cars crossing the bridge, the bridge bearings effectively behaved as 'pin-pin', rather than the 'pinroller' arrangement indicated on the drawing.

(iv) a static load test using an unloaded truck is carried out where mid-span displacement and bearing movement are monitored

(v) the data from (iv) indicated that under truck loading the bearings no longer behaved as 'pinpin', instead they behave as something closer to 'pin -friction roller', so the model is further updated to allow for friction in the roller, resulting in an accurate 'static model', which we refer to as Model 2.

(vi) To try and check that parameter compensation was not occurring in Model 2, a second load test using a loaded truck is carried out where mid-span displacement and bearing movement are again monitored, and it is shown that Model 2 still provides accurate predictions. Admittedly this is not definitive proof that parameter compensation is not occurring but it does give confidence that if parameter compensation is occurring it is not detrimental in the loading rang of interest. Note, similar to [20], in this study parameter compensation describes the situation where an error in one parameter (e.g. too large a value of Young's modulus of steel) is compensated for by an error in another parameter (e.g. too small a value of Young's modulus of concrete).

In broad terms steps (i)-(vi) are covered in Sections 2-6 as follows. Section 2 describes the bridge used in the case study and the initial modal test carried out on the bridge, including displacement measurements taken at the bearings (step (i)). Section 3 describes the finite element models prepared (Model 0 and Model 1 ), the updating procedure used and the results observed, i.e. how close the frequencies of the updated model are to the measured frequencies (Steps (ii) \& (iii)). Sections 4-6 describe the load tests undertaken including the measurements recorded, the model updating carried out, and compares the field measurements to the corresponding FE model predictions (steps (iv)-(vi)).

It should be noted that the model updating procedures in this paper have deliberately been kept relatively simple. This is because the aim of the paper is to demonstrate the improvements that can be brought to an updated FE model by including bearing measurements in the suite of field tests, even when using relatively simple updating procedures. However, including bearing measurements in more sophisticated model updating procedures such as model falsification [20]-[24], Bayesian methods [25], or other methods discussed in Section 1.1 is likely to bring even larger improvements. 


\subsection{Modal data collected on bridge prior to FE model updating}

\subsection{Bridge used in case study}

The bridge used in this case study is shown in Fig. 1 and a plan view of the bridge is depicted in Fig. 2. The bridge is a half-through steel girder bridge simply supported at both ends and it spans $36 \mathrm{~m}$. The concrete deck is $7.6 \mathrm{~m}$ wide, $200 \mathrm{~mm}$ deep, and is supported on a series of $450 \mathrm{~mm}$ deep steel beams spanning transversely between the main girders which are approximately $2 \mathrm{~m}$ deep. To carry out model updating it was necessary to collect data on deck acceleration and bearing displacements. The procedure for collecting these data is described in sections 2.2 and 2.3 respectively.

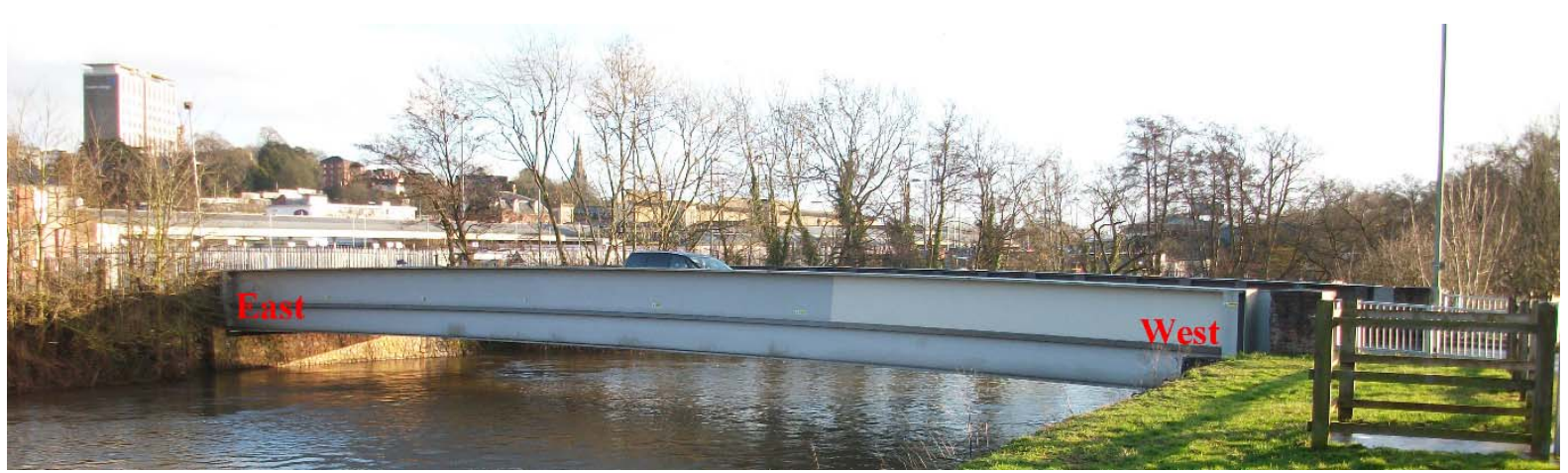

Fig. 1, North Elevation of the bridge used in the case study.

\subsection{Modal test on bridge}

The frequencies and mode shapes for the bridge have been established in an earlier study [26]. However, to allow the mode shapes to be understood a brief summary of the modal test and the analysis is provided. Fig. 2 shows a plan view of the bridge and the locations where accelerometers were placed. Accelerometer locations $U, V \& W$ were at the $1 / 4$ point, mid-span and $3 / 4$ point of the deck on the north side of the bridge, locations X-Z were at the same longitudinal positions on the south side of the bridge. The data logging station was set up at the northwest corner of the bridge as indicated in the figure.

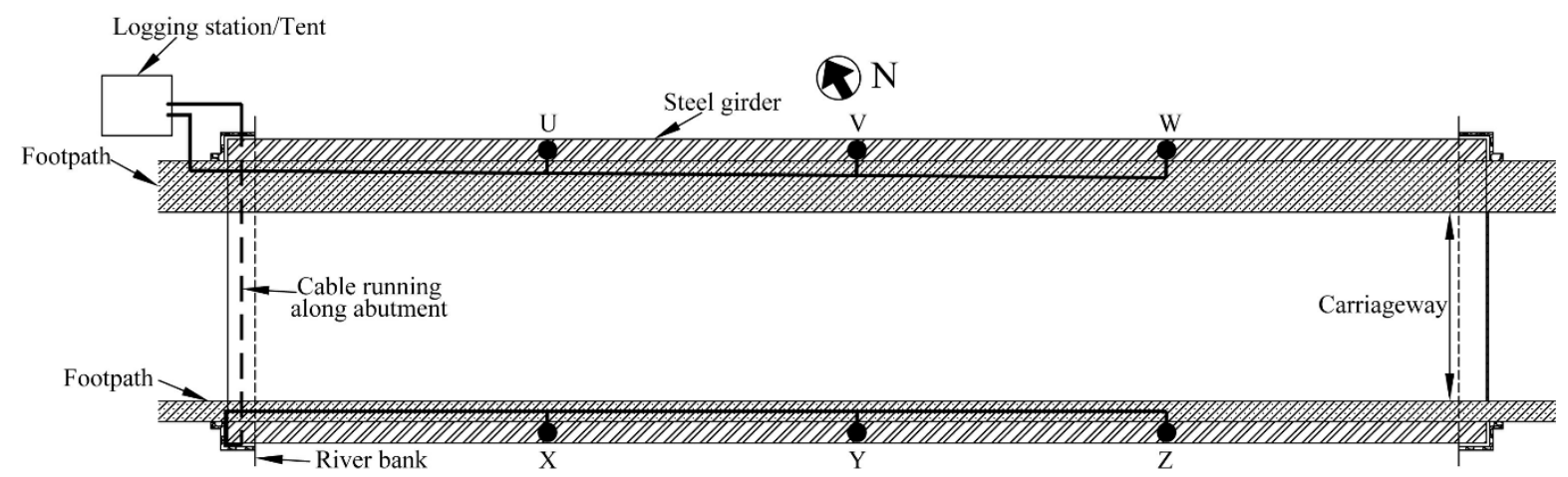

Fig. 2, Schematic of the accelerometer locations U-Z and corresponding cabling arrangement. 
The method used to identify the mode shapes is the NEXT/ERA operational modal analysis procedure [27]. This is one of several possible operational modal analysis procedures [28]-[30] and was used here due to long experience in its use and implementation in bespoke software [31]. Further details on the modal test on the bridge can be found in [26]. The mode shapes, frequencies and damping ratios obtained in the test are presented in Fig. 3

152

(a)

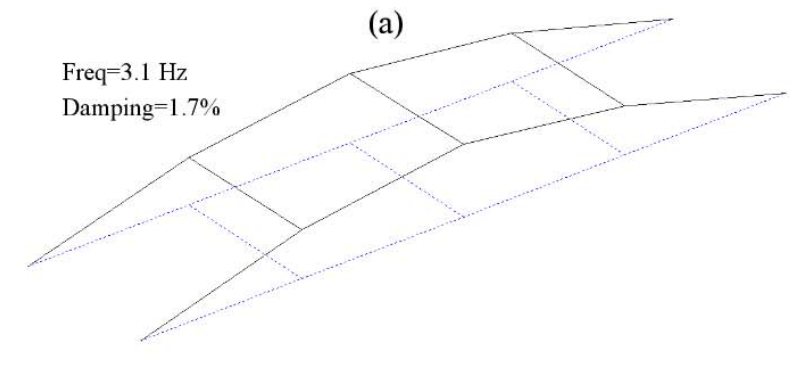

(c)

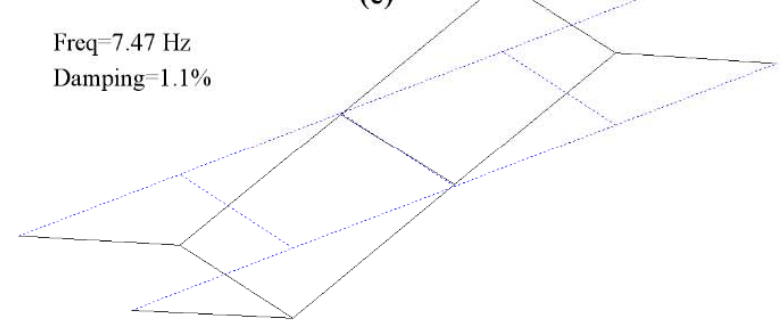

(e)

Freq $=13.8 \mathrm{~Hz}$

Damping $=0.84 \%$

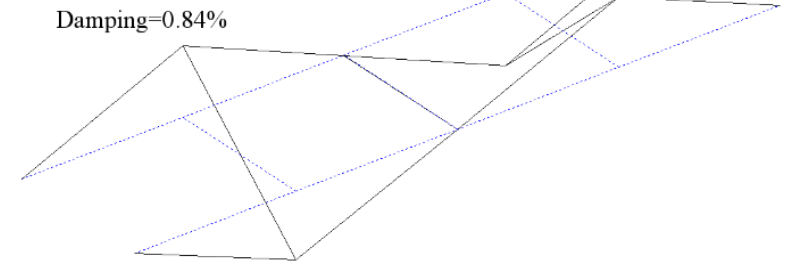

(b)

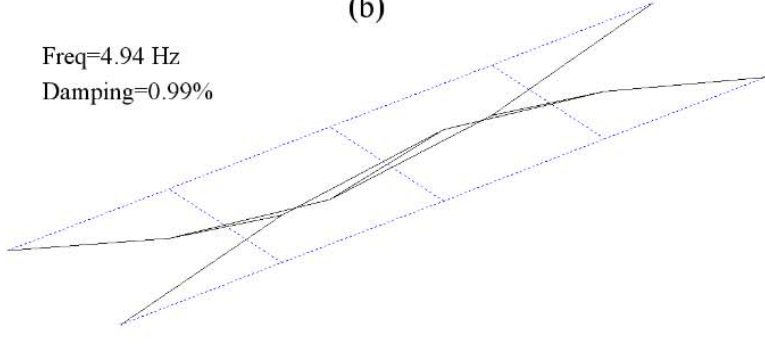

(d)

Freq $=11.3 \mathrm{~Hz}$ Damping $=1.9 \%$

Fig. 3, Bridge mode shapes identified by modal test: (a) First bending mode, (b) First torsion mode, (c) Second bending mode, (d) Third bending mode, (e) Second torsion mode.

\subsection{Bearing movements}

As well as the modal test, movement of the bearings was also studied on the same day as it is well known that boundary conditions play a big role in the behaviour of the bridge. The expansion joint shown in Fig. 4(a) is on the east end of the bridge which is on the left side of the image in Fig. 1. At the east end, the deck is supported on the two steel sliding bearings shown in Fig.4(b), with the bearings under the north and south beams shown in the foreground and background of the image, respectively. The bearing movement was recorded using an LVDT to measure the relative movement between the end of the beam and the concrete curtain wall on the abutment. The experimental 
setup of the LVDT is shown in Fig. 4(c) where the tip of the LVDT is touching the curtain wall and the body of the LVDT is supported on a retort stand which is attached to the end of the beam using a magnet. As well as measuring the translation of the bearing, the temperature of steel at the north east corner was also recorded during the modal test. The thermocouple used to record this temperature is attached to the steel beam using the white tape in the right of the image in Fig. 4 (c). The bearing movement and the corresponding steel temperature were recorded from 10am until $5 \mathrm{pm}$ on the day of the test, and the data are presented in Fig. 4(d). In the figure the bearing translation and surface temperature of the steel is plotted with respect to the left and right axes, respectively. Broadly speaking, the movement of the expansion joint/bearing is proportional to temperature, which is to be expected. However, interestingly the movement of the joint/bearing does not appear to be smooth, instead as the deck is expanding the joint appears to move in a kind of 'stepped' fashion. This indicates that there is a significant degree of friction/restraint in the bearing/expansion joint system and that as the pressure due to thermal expansion builds up the restraining force provided by the bearing will increase correspondingly. Then as the restraint can no longer hold the force due to thermal expansion the bearing will move and the process starts again. This results in a characteristic 'stick-slip' behaviour. These discreet periods of apparent restraint are found to be important when modelling the bridge and will be discussed further in later sections. Finally it should be noted that the LVDT was mounted slightly below the centroid of the main girder and therefore, when the bridge is heavily loaded and the ends of the deck rotate, some translation will be recorded on the LVDT. Ideally, when tracking thermal movements the LVDT would be placed at the centroid but in this case that was not practicable, as the curtain wall serving as a point of reference did not go all the way up to the centroid, so the LVDT was placed as close as possible to the centroid. If the plot of displacement in Fig $4(\mathrm{~d})$ is examined it can be seen that there are some localised spikes in displacement and these are believed to be due to heavy short duration loading on the bridge due to traffic congestion and/or heavy vehicles. The bridge is in an urban area and there are periods during the day when the traffic is stationary on the bridge due to congestion. 
(a)

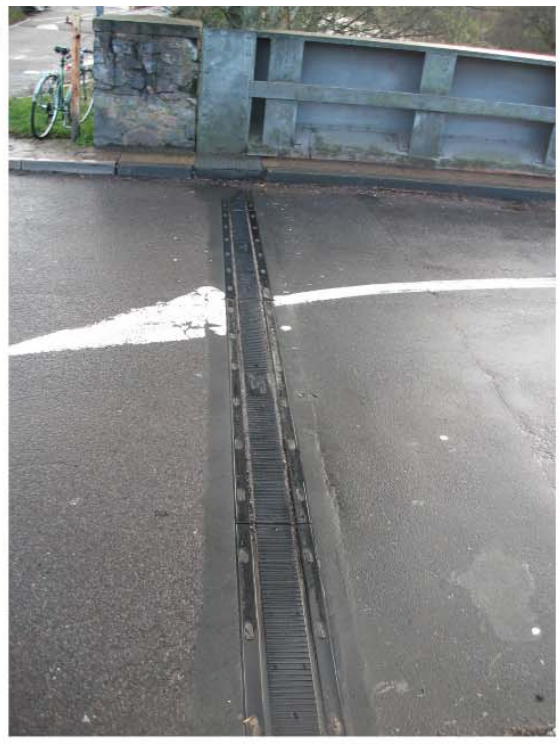

(c)

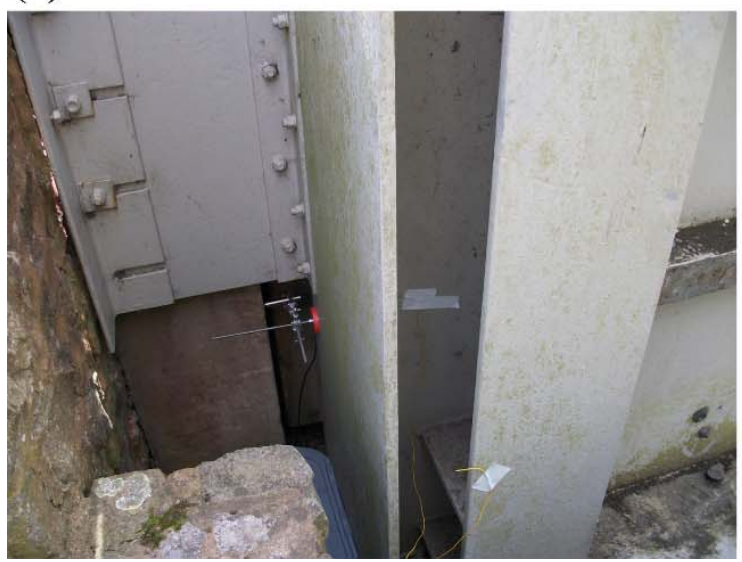

(b)

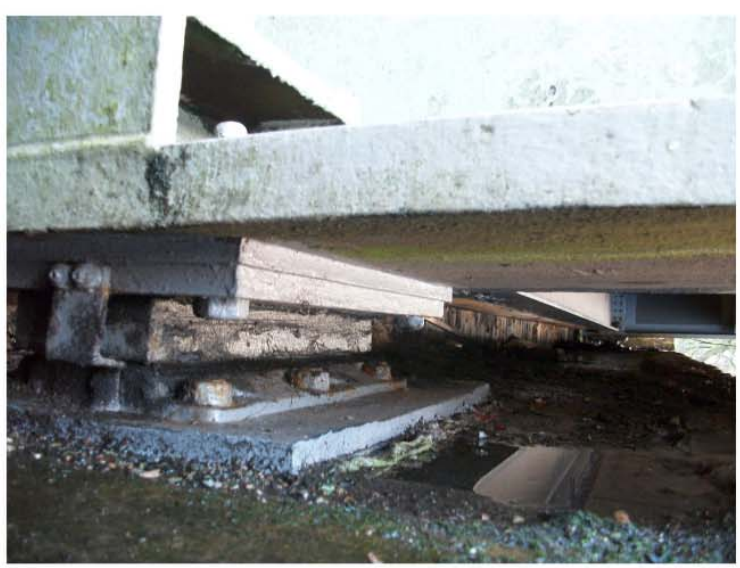

(d)

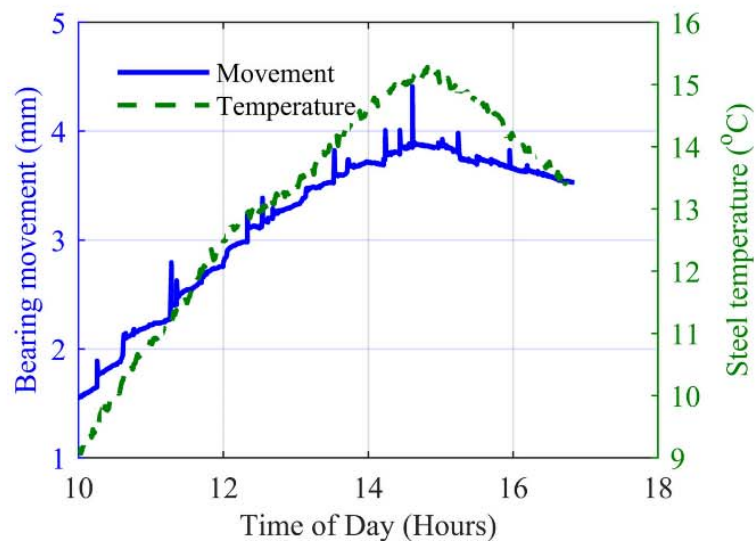

Fig. 4, Bridge bearings/expansion joints and associated monitoring, (a) expansion joint looking south, (b) sliding bearings on east abutment looking south, (c) LVDT mounted on east end of north girder (d) bearing movements and temperature variation observed during test.

\subsection{Finite element modelling for dynamic model}

Having collected the field data a Finite Element (FE) model of the bridge was prepared and updating procedures were implemented to try and get the model response to match the behaviour observed on site. The model and the updating procedures used are described in this section.

\subsection{Ansys models}

The bridge surface is shown in Fig. 5(a) and the corresponding FE model is shown in Fig 5(b). The FE model of the bridge was created using ANSYS 14.5. The geometry was obtained from design drawings provided by the bridge operator. When preparing a FE model knowing the exact elastic moduli and mass densities to use for steel and concrete is challenging. However, there are well established ranges of values that are widely accepted [32] and in this study commonly used values within these ranges were selected. Therefore steel members were modelled using an elastic modulus of $206 \mathrm{GPa}$ and a mass density of $7849 \mathrm{~kg} / \mathrm{m}^{3}$. The $200 \mathrm{~mm}$ thick concrete deck was modelled using an elastic modulus of $30 \mathrm{GPa}$, and a mass density of $2403 \mathrm{~kg} / \mathrm{m}^{3}$. The asphalt surfacing layer is indicated on the drawings to be $100 \mathrm{~mm}$ thick and is considered as an additional 
density to the concrete deck, but it was not assumed to contribute to the stiffness of the concrete deck. Based on this approach the initial value of deck density used in the model was $3604 \mathrm{~kg} / \mathrm{m}^{3}$. Admittedly this approach of assuming no stiffness contribution from the bituminous surfacing is a simplification, as in reality it could potentially add some stiffness to the bridge deck. However, to date in the literature there has been little/no research carried out on exactly how much of a contribution to deck stiffness the bituminous surfacing makes, and consequently most researchers ignore it. There are a number of reasons for this but two common engineering reasons relate to shear connection and the integrity of the bitumen surfacing. Firstly for the stiffness contribution of the bitumen to be included in the model there needs to be an adequate shear connection between the bitumen and the concrete deck so that it will behave compositely. This is by no means assured because factors such as the, finished surface of the concrete deck, presence of a water proofing membrane, bitumen binder type and content, weather conditions at time of paving and conditions since pavement laying (particularly drainage within the surfacing) have a big effect on this. Secondly if the deck surfacing has cracks running in the transverse deck direction it is likely that the strain in the extreme fibre of the surfacing will be significantly lower than that predicted by conventional beam bending theory. This is due to the fact that the lengthening and shortening movements in the top fibre of the surfacing due to deck hogging and sagging will be accommodated by the cracks and hence conventional bending strain behaviour will not be mobilised.Therefore for consistency with previous work the stiffness contribution of the bitumen is not considered in this study. However, despite there being engineering reasons behind the decision to omit the stiffness of the bitumen surfacing this is a source for uncertainty in the model. Similarly including the stiffness of the bitumen would also be a source of uncertainty in the model. From the bridge drawings it is known that the bearing on the west end of the bridge is a 'pinned bearing' and the east end is a 'roller' or 'sliding' bearing.

To examine the effects of different modelling techniques, initially two FE models were built based on different element types, (in effect these models are subsets of Model 0 ). In in the first model, which is referred to as 'beam and shell' (B\&S) model, the main girders and the transverse beams are modelled using beam elements and the bridge deck is modelled using shell elements. In the second model, which is referred to as the 'plate' model, thin shell elements are used to model all parts of the bridge. In the B\&S model, the neutral axis of the beam elements is drawn in the same plane as the mid-span of the shell elements as a default and thus an offset was applied to the beam elements to accurately model a beam-plate assembly (beam attached to the bottom of the plate). In the B\&S model the vertical web stiffeners on the main girders which can be seen in Figs. 5(a), are not included in the simulation. In the plate model, the shell elements used to simulate the deck were set in the centre line and constrained via nodal coupling with the nodes in the transverse beam to achieve the correct geometry. The stiffeners to the steel girders were also modelled using shell elements. In effect the B\&S model and the plate model were our initial attempts at developing a Model 0 referred to in section 1.2. The benefit of using two relatively common modelling approaches is that it should allow us to identify which basic (un-updated) model best 'approximates' the observed behaviour. Consequently it makes it more likely that this modelling approach is the more accurate representation of the true behaviour of the structure. 
(a)

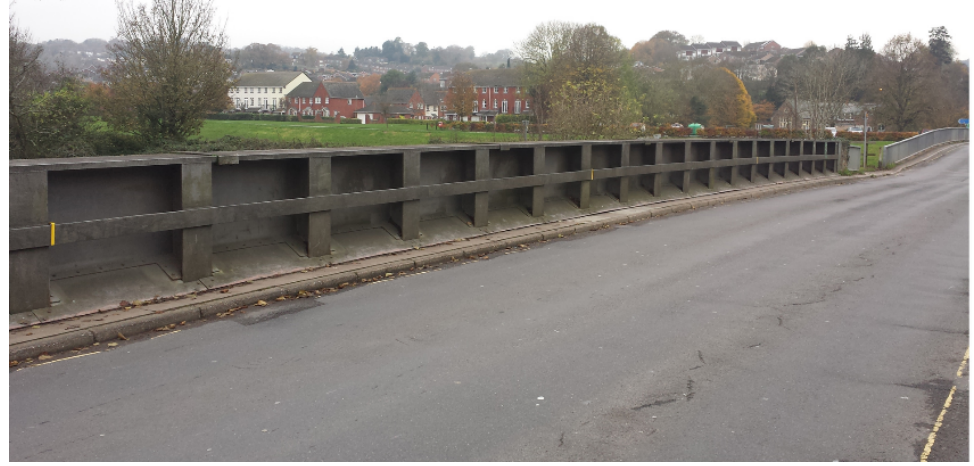

(b)

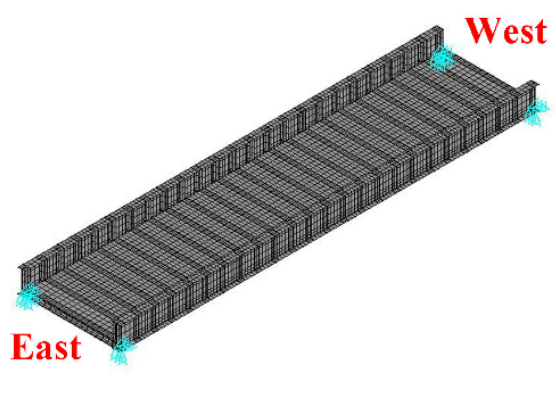

Fig. 5, Bridge and model, (a) Bridge deck and south girder, (b) Finite element model of the bridge.

Based on the information from the bridge drawings, both models were initially assumed pinned at the West end and as rollers at the East end. The resulting mode shapes from the Plate model are shown in the left column of the Table 1. For convenience, the measured mode shapes (previously shown in section 2) are reproduced in the right column of Table 1. Examining these plots shows that the shape of the modes predicted by the Plate model match quite well with those measured on site. The mode shapes predicted by the B\&S model are very similar to Plate modes shown in Table 1 so they are not shown.

Table 1, Mode shapes from FE model and site data

\begin{tabular}{|c|c|c|}
\hline $\begin{array}{l}\text { Mode } \\
\text { No }\end{array}$ & Mode shape from Ansys Plate model & Mode shape from site data \\
\hline 1 & $1^{\text {st }}$ Bending & \\
\hline 2 & $1^{\text {st }}$ Torsion & \\
\hline
\end{tabular}




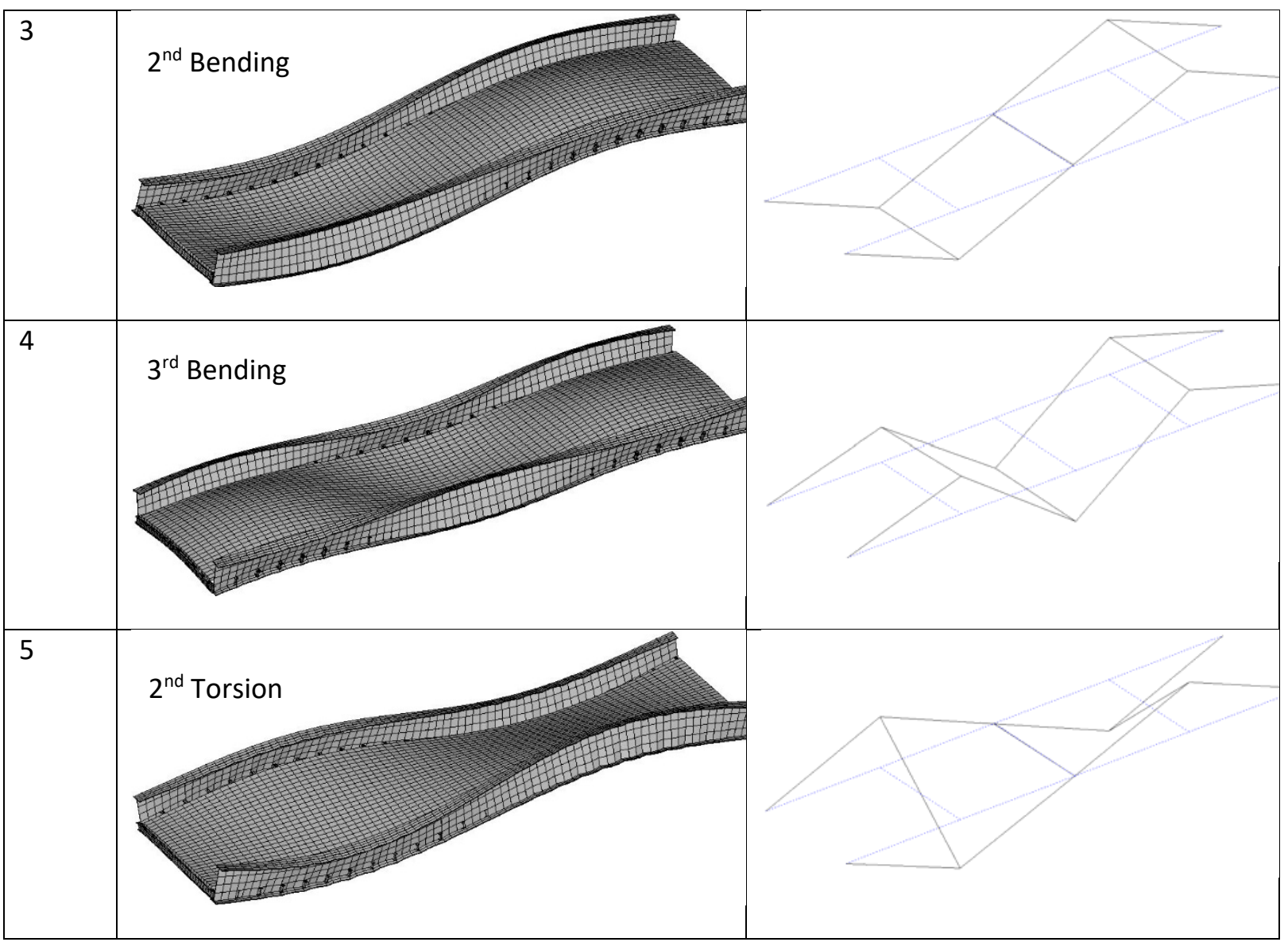

While the basic mode shapes from the model agree well with those observed on site there is not such good agreement between the associated frequencies. This point is illustrated in Table 2 which shows the measured frequencies and the corresponding frequencies predicted by the models. The text in bold shows the measured frequency, the text in the shaded rows shows the frequencies predicted by the finite element models when pin-roller boundary conditions are assumed. The unshaded rows show the frequencies when the boundary conditions are assumed pinned-pinned.

When pin-roller boundary conditions are assumed (shaded rows) it can be seen that the frequencies predicted by the beam and shell model are different to the frequencies predicted by the plate model, especially for modes 2 and 4 where the plate model predicts appreciably higher frequencies. The primary reason for this is believed to be due to the fact that the plate model takes account of the web stiffeners in the main girders whereas the B\&S model does not. The main girders of the bridge are $2.1 \mathrm{~m}$ deep therefore the torsional stiffness of the girder likely plays a role in several of the modes and therefore for some modes the stiffeners are likely to make an appreciable contribution to the overall stiffness of the system.

While it is interesting to look at the differences between the frequencies predicted by both models, more important is the differences between both FE models and the frequencies measured on site. When pin-roller boundary conditions are assumed, both FE modes significantly underestimate the frequencies of modes $1 \& 2$, and overestimate the frequencies of modes $3 \& 5$. Due to the stepped nature of the displacement pattern evident in Fig. $4(\mathrm{~d})$ it is reasonable to assume that the support conditions during the monitoring period were in reality very close to pinned-pinned when the bridge 
was lightly loaded or completely unloaded. Therefore the two bottom rows of Table 2 show the frequencies predicted by both FE models for pin-pin bearing conditions. Now modes 1 and 2 from the plate model are quite close to the experimentally measured values. The frequency of mode 3 is still too high but has been largely unaffected by assuming pin-pin boundary conditions. Mode $4 \& 5$ frequencies, already too high have been further increased by assuming pin-pin boundary conditions, but not by a significant amount. So far it appears that using a plate model and assuming pin-pin boundary conditions is reasonably accurate at capturing the dynamic properties for lower frequency modes under relatively light loading. However, to try for better agreement between measured and FEM modes the better performing pin-pin 'plate' model will be updated using the procedure described in the next section. For convenience and consistency with the steps described in Section 1.2 the plate model with pin-roller boundary conditions is considered as Model 0 , i.e. the model built off the drawings without updating.

Prior to getting into the details of model updating it is useful to step back for a moment to reflect on the bigger picture. Having observed the differences described above it is clear that no combination B\&S or Plate and 'pin-roller' or 'pin-pin' will provide the perfect model. Moreover it is unlikely that even if deck density could be measured accurately and input into the model that it would provide a perfect match for all five frequencies. Particularly when one considers that on a structure as large as a bridge there are likely to be local variations in mass and stiffness. Therefore even after the model is updated it is unlikely to perfect. However, in this instance and in many others faced by engineers, the challenge is to develop as accurate a model as possible within the constraints of the data available and that is the approach being followed in this study.

It should be noted that while assuming pinned-pinned is reasonable when the bridge experiences light load such as cars and light trucks, which was the case for most of the acceleration data collected here, it is not an appropriate if the bridge has significant load on it such as heavy goods vehicles (HGVs). This is because when there is significant load on the bridge it is likely to behave something closer to pin-roller, as evidenced by the localised sharp peaks in Fig. 4(d). Further evidence and discussion on this point is presented in Sections 5 and 6 where a load test is carried out on the bridge.

Table 2, Measured frequencies and model predicted frequencies for different models and end conditions.

\begin{tabular}{|c|c|c|c|c|c|c|}
\hline & & \multicolumn{5}{|c|}{ Frequency $(\mathrm{Hz})$} \\
\hline & $\begin{array}{l}\text { Assumed end } \\
\text { conditions }\end{array}$ & $\begin{array}{l}\text { Mode } 1 \\
\left(1^{\text {st }}\right. \\
\text { Bending })\end{array}$ & $\begin{array}{l}\text { Mode } 2 \\
\text { (1 } \\
\text { Torsion) }\end{array}$ & $\begin{array}{l}\text { Mode } 3 \\
\text { (2 } \\
\text { Bending) }\end{array}$ & $\begin{array}{l}\text { Mode } 4 \\
\text { (3 } \\
\text { Bending) }\end{array}$ & $\begin{array}{l}\text { Mode } 5 \\
\text { ( }^{\text {nd }} \\
\text { Torsion) }\end{array}$ \\
\hline Measured & Not applicable & 3.08 & 4.945 & 7.470 & 11.346 & 13.80 \\
\hline$B \& S$ & Pin-roller & 2.537 & 4.035 & 7.671 & 10.335 & 14.262 \\
\hline Plate & & 2.453 & 4.413 & 7.863 & 11.678 & 14.145 \\
\hline$B \& S$ & Pin-pin & 2.689 & 4.207 & 7.673 & 10.358 & 14.312 \\
\hline
\end{tabular}




\begin{tabular}{|l|l|l|l|l|l|l|}
\hline Plate & 3.225 & 4.962 & 7.880 & 11.922 & 14.512 \\
\hline
\end{tabular}

\subsection{Model updating procedure used and results obtained}

When carrying out model updating the parameters commonly updated are: elastic modulus of concrete $\left(E_{c}\right)$, elastic modulus of steel $\left(E_{s}\right)$, density (self-weight) of concrete, and density (self-weight) of steel $\left(D_{s}\right)$. Note, as pointed out at the start of section 3.1 the bituminous surfacing is assumed to provide no stiffness to the deck but it's mass contribution is taken into account. As the mass of the surfacing and the concrete is being attributed to the concrete deck this deck mass variable is referred to as density of deck $\left(D_{d}\right)$. To avoid parameter compensation that can occur when more than one parameter is updated it was decided to update only one parameter. Of the commonly used parameters it was felt that the greatest uncertainty was regarding the density of the deck $\left(D_{d}\right)$, as without drilling the slab and the pavement at several locations it is very difficult to be certain of the pavement thickness or indeed the slab thickness. Therefore the density of the deck $\left(D_{d}\right)$ was adjusted to obtain a good fit in natural frequency. In this model $E_{s}$ is taken as $206 \mathrm{GPa}, E_{c}=30 \mathrm{GPa}$, and $D_{s}=7,800 \mathrm{~kg} / \mathrm{m}^{3}$. Finally it is important to note that while only updating one parameter avoids parameter compensation, the issue of parameter-prediction error compensation (PPEC) is still a risk. PPEC is where other errors in the model (e.g. geometry or stiffness) are compensated for by pushing the parameter being updated to an incorrect/untrue value. Unfortunately PPEC is an inherent risk in FE model updating and therefore can't be avoided completely. However, starting with a basic (unupdated) FE model that is pretty close to the observed behaviour and checking that the updated parameter is within a sensible range helps mitigate this risk.

The objective function is built up by the sum of the squared residuals between the measured modal frequencies (the first five) and the numerical predictions. Pattern search technique [33] was implemented for the optimisation process, which is suitable for the global optimisation with a simple tactic and derivative-free. The focus of this study is on the boundary conditions and it was felt that using a relatively simple model updating procedure was the best way to examine the impact of the boundary conditions. Constrained bounds were applied to the updated parameter with the lower and upper bounds at 0.5 and 1.5 times of the initial value.

The initial value in $R 0$ was $D_{d}=3604.5 \mathrm{~kg} / \mathrm{m}^{3}$. After the updating process, $R$ converged to $D_{d}=4,153$ $\mathrm{kg} / \mathrm{m}^{3}$. This indicates that $D_{d}$ is $15 \%$ higher than one might expect based on the drawings. This equates to an extra $50 \mathrm{~mm}$ of surfacing on the bridge deck, i.e. $150 \mathrm{~mm}$ rather than the $100 \mathrm{~mm}$ shown on the drawings. Considering that the bridge is likely to have undergone multiple resurfacings since it was originally constructed such an increase in surfacing does not seem unreasonable. Alternatively the extra mass could be due to a slightly thicker concrete deck and/or deeper footpaths both of which are conceivable. Table 3 shows that after updating there is good agreement between the measured frequencies and those predicted by the updated model. However, without having the information on the bearings it is likely to have been quite difficult to get the frequencies to match and still keep the model parameters $\left(E_{s}, E_{c}, D_{s}\right.$, etc) within a sensible/credible range of values. This assertion is based on the fact that in Table 2 when pin-roller boundary conditions are assumed the FE frequency predictions for modes $1 \& 2$ are appreciably lower than measured values, but the FE frequency predictions for modes 3-5 are all marginally higher, i.e. it would be difficult to increase the FE predictions for modes 1 \& 2 and 
simultaneously reduce the FE frequency predictions of modes 3-5. For ease of referencing we will call this updated model which assumes pinned-pinned boundary conditions as Model 1 . The mode shapes from Model 1 are very similar to those shown in the right column of Table 1, i.e. the mode shapes from Model 1 show very good agreement with the mode shapes measured on site.

At this stage when a good match has been observed between the measured and model predicted frequencies it is important to point out that as with all model updating it is helpful to maintain a healthy degree of scepticism about the accuracy of the model. For example it is possible that due to omitting the stiffness contribution of the surfacing the possibility exists that we have an incomplete model that is being compensated by a biased parameter value. However, the fact that there is experimental evidence that the bearings are behaving as pin-pin (Fig. 4(d)) and that when these boundary conditions were implemented in a model that assumed no stiffness contribution from the surfacing (bottom row of Table 2) all the model predicted frequencies were higher than the corresponding measured values. If a stiffness contribution of the bitumen had been included in the model the predicted frequency values would have been higher, i.e. even further way from the measured values. Hence assuming no stiffness contribution from the bitumen surfacing in the model appears reasonable. However, there is no way of knowing definitively if the model is absolutely correct. Therefore having established what looks like a credible FE model for dynamic predictions (Model 1) the next step was to see if this could be evolved to provide accurate predictions of static behaviour and this is addressed in the next section.

Table 3, Frequencies after model updating.

\begin{tabular}{|l|l|l|l|l|l|l|}
\hline & & \multicolumn{5}{|c|}{ Frequency (Hz) } \\
\hline & $\begin{array}{l}\text { Assumed } \\
\text { end } \\
\text { conditions }\end{array}$ & Mode 1 & Mode 2 & Mode 3 & Mode 4 & Mode 5 \\
\hline Measured & $\begin{array}{l}\text { Not } \\
\text { applicable }\end{array}$ & $\mathbf{3 . 0 8}$ & $\mathbf{4 . 9 4}$ & $\mathbf{7 . 4 8}$ & $\mathbf{1 1 . 4}$ & $\mathbf{1 3 . 7 8}$ \\
\hline Plate & Pin-pin & 3.076 & 4.826 & 7.486 & 11.339 & 14.085 \\
\hline $\begin{array}{l}\text { Difference } \\
\text { in Hertz }\end{array}$ & N/A & 0.004 & 0.114 & 0.006 & 0.061 & 0.305 \\
\hline $\begin{array}{l}\% \\
\text { Difference }\end{array}$ & N/A & $0.141 \%$ & $2.314 \%$ & $0.081 \%$ & $0.533 \%$ & $2.213 \%$ \\
\hline
\end{tabular}

\subsection{Procedure for static load tests}

Having shown that by monitoring the bearing movement and updating the FEM parameters it was possible to obtain reliable representation of modal properties, the next step is to attempt to achieve a similar result for a 'static' model. To check this, it was necessary to carry out two separate load tests on the bridge. The truck used in both tests was the same (four axle aggregate truck) but in the first test the truck was unloaded (gross weight $\approx 12$ tonnes) and in the second test it was loaded 
(gross weight $\approx 32$ tonnes). Data from the first test was used to update the model and data from the second was used to check the model. The authors feel that carrying out two different load tests is important, because if there are significant parameter compensation errors in the updated model, performing the second test should help to expose this problem. Admittedly the second test is not a guarantee of exposing a potential problem as conceivably the bias could be the same for both load tests. However, for a complex structure such as a bridge there is a reasonable chance that the second test will give some indication if there is a serious error. Details on the procedure for carrying out the two load tests and the results obtained are described in the remaining sections of this paper. Details on the measuring systems used, the test truck and stopping locations are described in this section. Subsequently sections 5 and 6 report the experimentally measured bridge displacements and corresponding FE model predictions for the tests with the unloaded and loaded trucks respectively

\subsection{Measuring systems used}

Fig. 6 shows a schematic of the bridge and the three different measuring systems used on the bridge. Details on the camera system to measure mid-span displacement, the Linear Variable Displacement Transducers (LVDTs) used to measure bearing movement at the east end of the deck, and the go-pro action camera used to track vehicle movements are provided in sections 4.1.1-4.1.3 respectively.
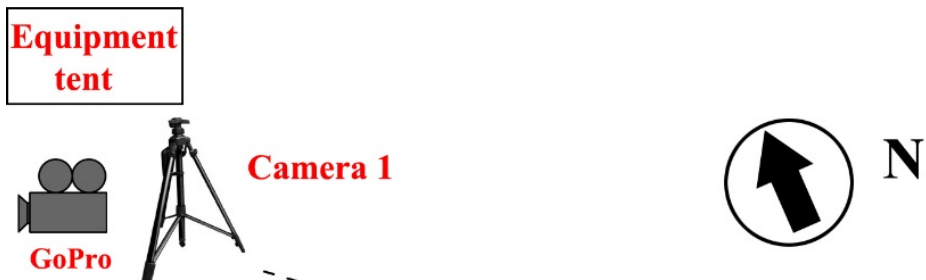
GoPro

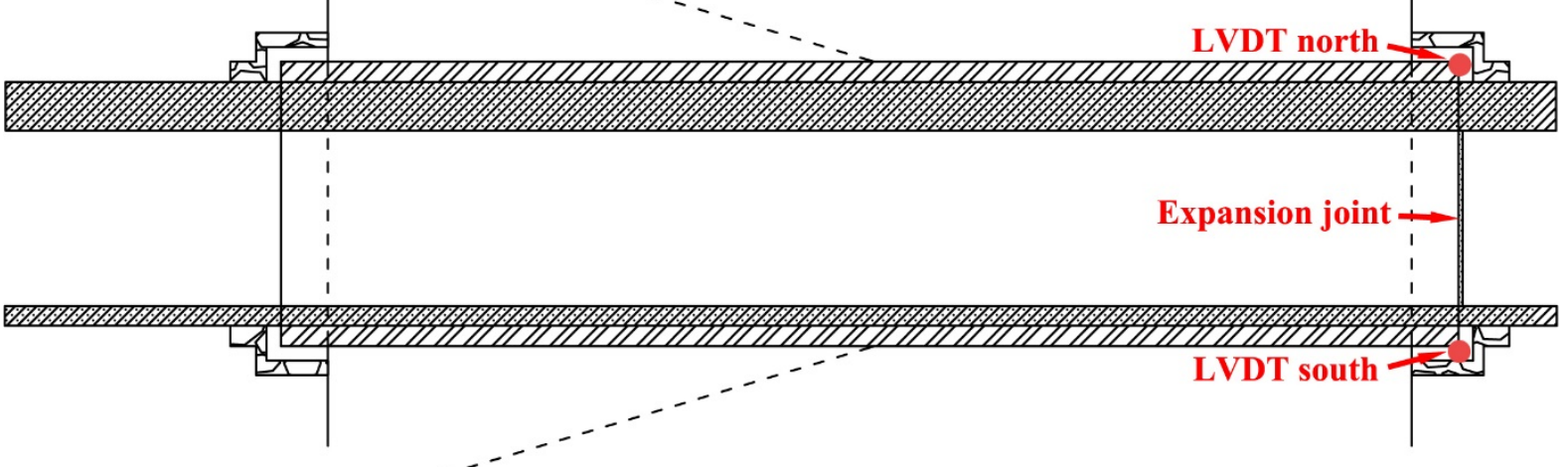

Camera 2

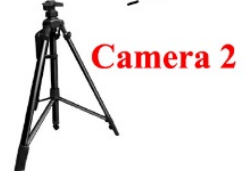

Fig. 6 Plan view of bridge and instrumentation setup 


\subsubsection{Imetrum camera system}

A commercial (Imetrum) multi-camera displacement tracking system was used to capture quasistatic response in the load test. Fig. 6 shows two cameras on the west bank of the river, one on the north side of the bridge (camera 1 ) and one on the south side (camera 2). Cameras 1 and 2 tracked the mid-span displacement of the north and south girders, respectively. The position of the equipment tent is also indicated in Fig. 6 and a photo of this tent is shown in Fig 7(a). Camera 1 can be seen on the yellow tripod just to the right of the tent. Fig. 7(b) shows the view from the tent, and the zone at mid-span to be tracked by the camera is shown circled. The insert in the figure shows the view from camera 1 of the artificial 'target' that was stuck to the web of the girder at mid-span. If there was sufficient natural texture on the girder an artificial target would not have been necessary. However, in this case the web had been painted so the surface was quite uniform and therefore a target was required. The target does not have to be concentric circles but such a pattern has been found to work well in the past and therefor was used in this test. The set up for camera 2 on the south side of the bridge was the same and a network cable connected camera 2 to the Imetrum logger in the tent. Having cameras on both sides of the bridge allowed us to track the total deflection of the bridge at mid-span.

(a)

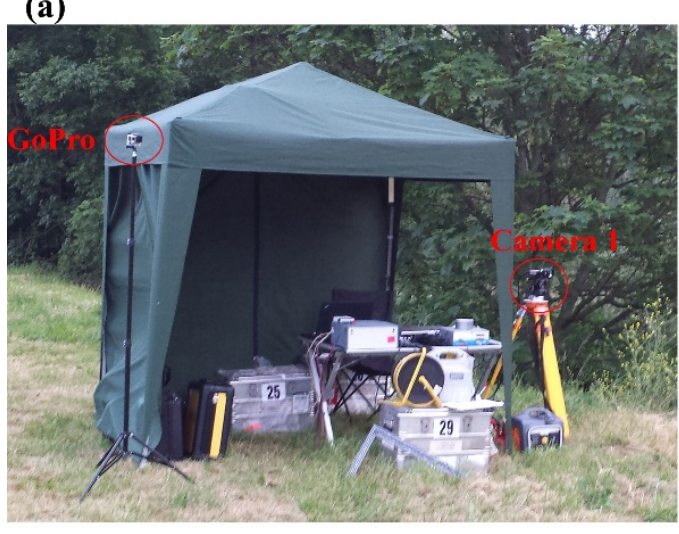

(b)

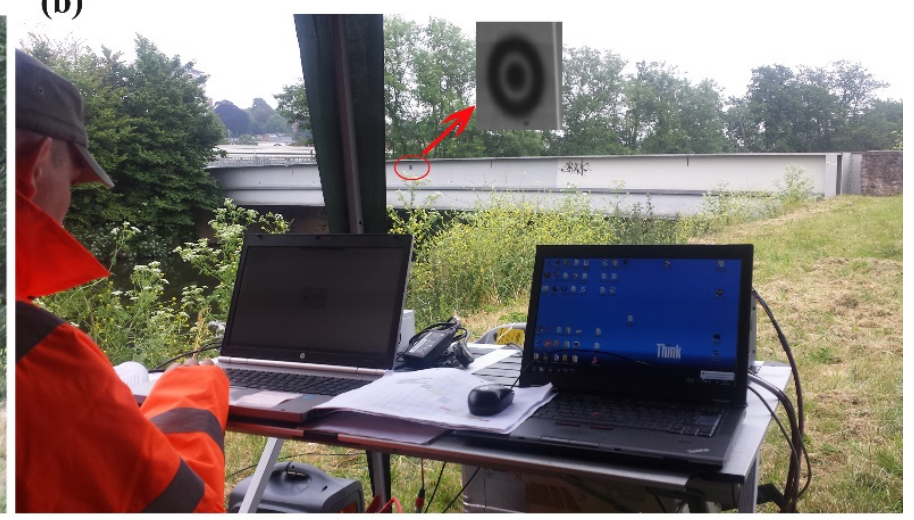

Fig. 7, Equipment tent looking north, (a) go-pro to the left of the tent and camera 1 to the right (b) view of the bridge from the equipment tent.

\subsubsection{LVDT}

The same LVDT system described in section 2.3 was used again in this test. However, unlike in section 2.3 where the LVDT was placed close as possible to the centroid of the girder, in this test the LVDT is placed approximately level with the bearings at the bottom of the girder. The reason for doing this was that in this test the objective was to monitor how the bearing was moving under truck loading so it made sense to put the LVDT approximately level with the bearing. Fig. 8(a) shows the set up at the east end of the North girder, the data logger can be seen in the foreground of the image and the LVDT at the bottom of the girder is shown circled. Fig 8(b) shows a zoomed in view of the LVDT where the tip is touching the concrete curtain wall on the abutment and the body of the LVDT is supported by a retort stand connected to the end of the girder. 
(a)

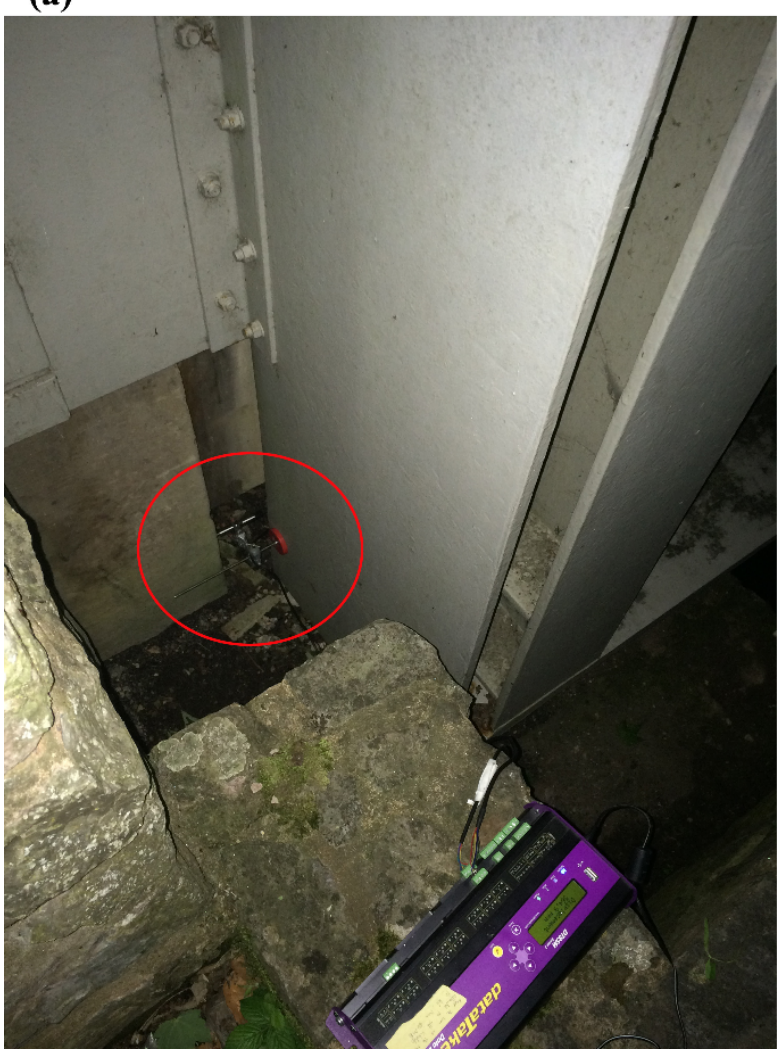

(b)

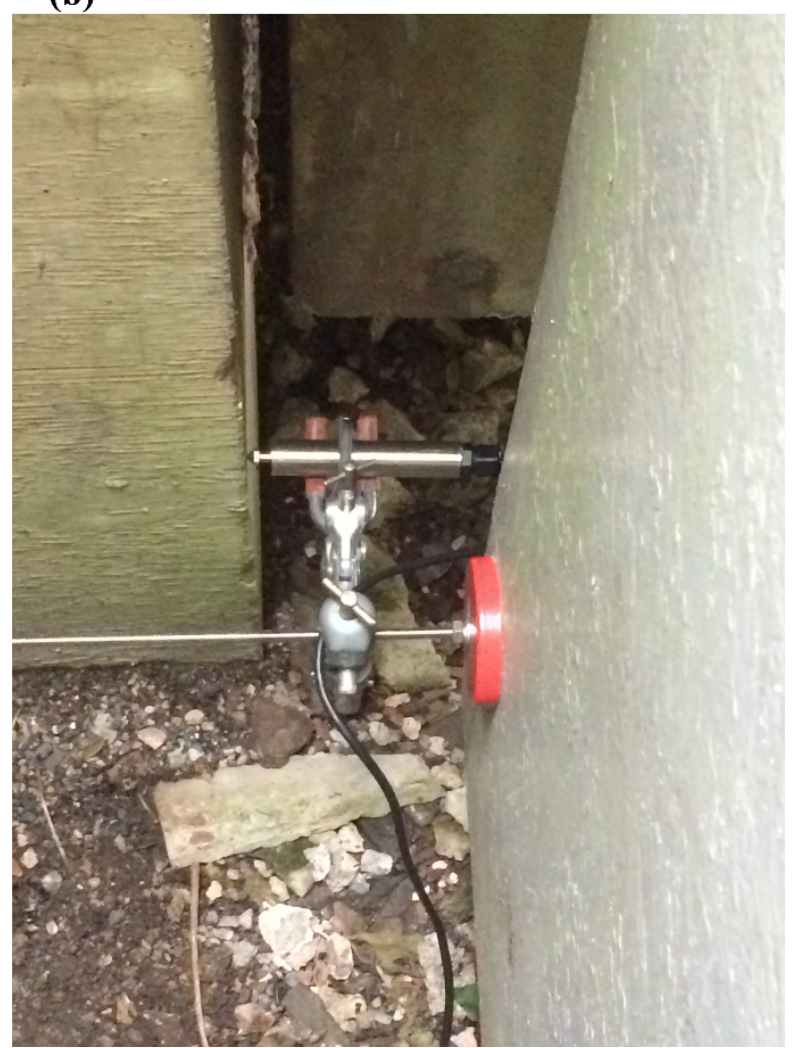

446 Fig. 8, LVDT system set up to measure bearing movement at the east end of the bridge, (a) overview of location of system, (b) close up view of the LVDT at the bottom of the girder.

\subsubsection{GoPro}

450 The GoPro action video camera was positioned to the left of the tent as shown in Fig. 7 and its role 451 was to record what was crossing the bridge during the test. Using a countdown system, the Imetrum cameras, the LVDTs and the GoPro were all switched on at approximately the same time. This means that in conjunction with notes taken on site footage from the GoPro could be used to identify what was happening on the bridge deck when a given peak in displacement is observed. As the syncing was manual rather than electronic the three systems were synchronised to one or two seconds, which was adequate for the purpose of the static load test. Fig. 9 shows an image from the GoPro. 


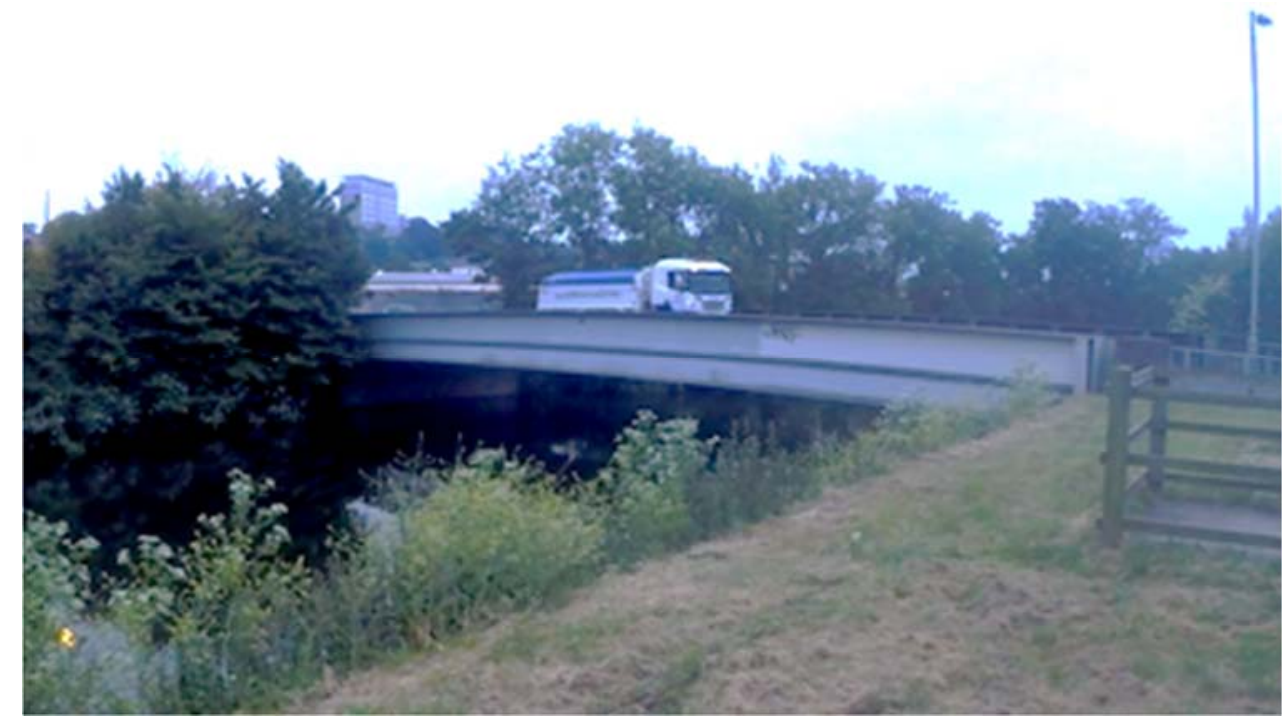

Fig. 9, View from GoPro camera.

461

\subsection{Truck information and stopping locations}

The truck used in the test was the four axle Scania P410 shown in Fig 10(a). In the first test the truck was unloaded and in the second test the truck was loaded. In this paper the loaded and unloaded trucks were measured to have a Gross Vehicle Weights (GVW) of 12T and 32T respectively. The individual axle weights are more difficult to measure directly however, the manufacturer data sheets provide accurate axle weights for when the truck is empty and fully loaded and these are shown in parts (b) and (c) respectively of Fig. 10. . If the truck was partially loaded then even if the GVW was known the axle weights could only be estimated.

(a)

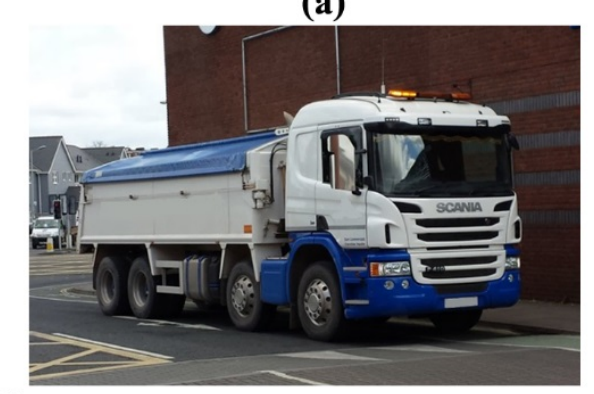

(b)

(c)
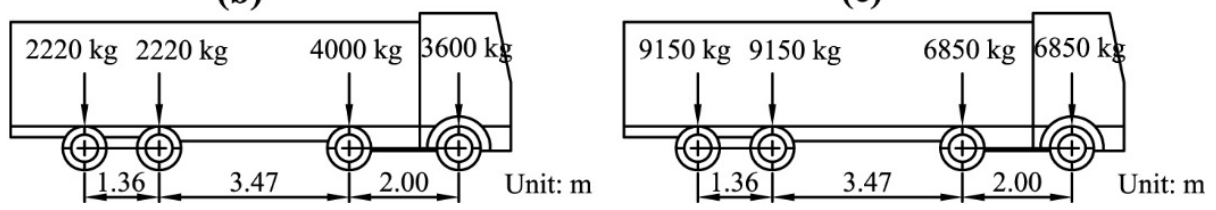

Fig. 10, Load arrangement of the truck used in the load test, (a) photo of truck, (b) axle weights and spacing's for unloaded truck Gross Vehicle Weigh (GVW) 12T (c) axle weights for loaded truck GVW $32 \mathrm{~T}$

474 The truck needed to be able to stop at a series of predetermined locations for measuring the 475 resulting displacement, so the road was marked with chalk to indicate to the driver where to 
position the front axle when stopped. Permission for full bridge closure was not obtained so it was not possible to drive the truck up the centre of the bridge, i.e. the truck had to adhere to the traffic lanes marked on the bridge. Therefore the chosen truck stop positions were A-F as shown in Fig 11. Positions A, B and C correspond to when the truck was on the North side of the bridge (travelling East) and with the centre of the truck at quarter-span, mid-span and 3-quarter span, respectively. In this study, for convenience the centre of the truck is considered as the midpoint between the $2^{\text {nd }}$ and $3^{\text {rd }}$ axles. Positions $D, E$ and $F$ are when the truck is on the South side of the bridge (travelling West) and the centre of the truck stops at quarter-span, mid-span and 3-quarter span respectively. Fig. 11 is a schematic, intended to allow the reader visualise where the truck stopped, i.e. the footprint of the truck, but is not drawn to scale (truck footprint is actually slightly bigger than shown in the figure). In the loading test the truck stops at a given location (A-F) for at least 10 seconds with no other traffic on the bridge.

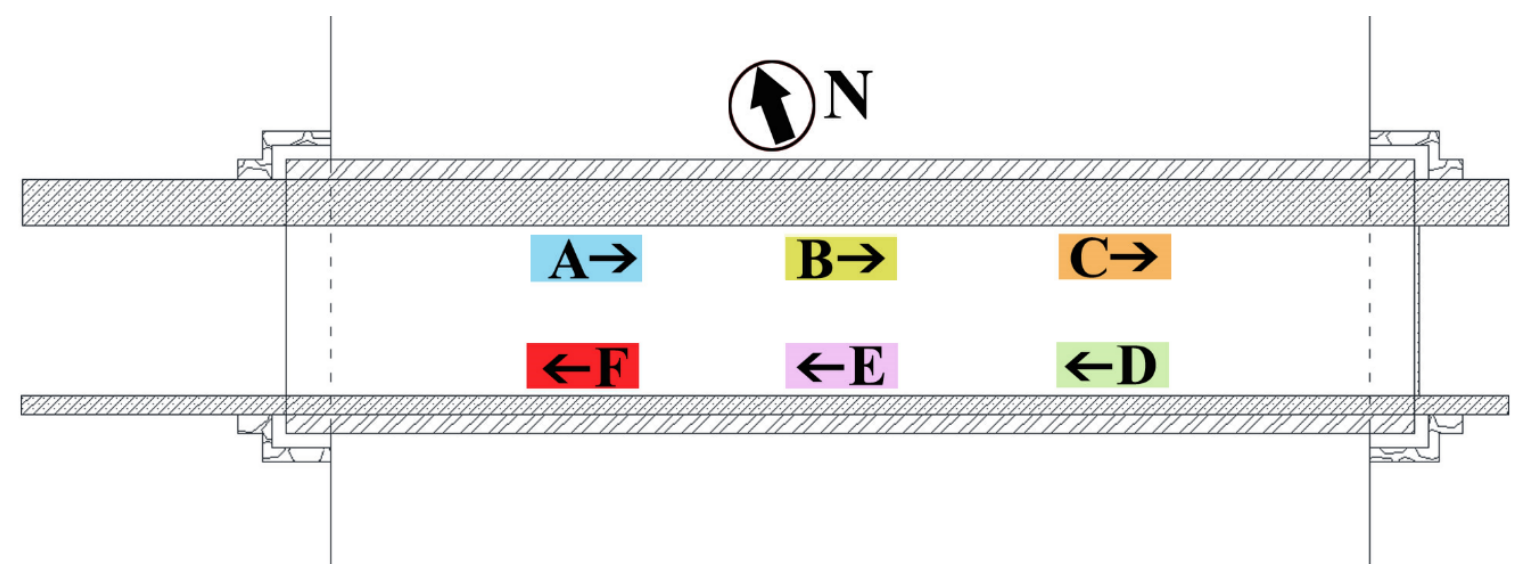

Fig. 11, Locations where the truck stopped during the load test.

\subsection{Static test with unloaded truck}

\subsection{Experimental results of test with unloaded truck}

For the purpose of the load test only the test truck should be on the bridge, but without full closure it was possible only to work within the traffic windows experienced on site. During the period when the test with unloaded truck was being carried out traffic was reasonably busy and we were only able to get uncorrupted measurements for mid-span stopping locations B and E (see Fig. 11).

The midspan displacement from the test is shown in Fig. 12(a). The truck started off on the west side of the bridge and was driving east before stopping at point $B$ at 30 seconds, pausing for approximately 12 seconds then moving off the bridge. When stopping at point $B$ the truck was positioned closer to the north girder (see Fig. 11) and this is reflected in the fact that for stopping location $B$ the mid span displacement for the north and south beams was approximately $3 \mathrm{~mm}$ and $1.9 \mathrm{~mm}$ respectively, i.e. the displacement for the north beam is larger. Fig. 12(b) shows the corresponding bearing movements for the same loading event and it can be seen that when the truck stopped at location $B$, bearing movements of $0.26 \mathrm{~mm}$ and $0.12 \mathrm{~mm}$ occurred in the north and south beams, respectively. The truck turned around and came back on to the bridge travelling west and stopped at location E between 130 seconds and 150 seconds. This resulted in mid-span 
displacements $1.7 \mathrm{~mm}$ and $3.1 \mathrm{~mm}$ respectively in the north and south girders, with corresponding bearing movements of $0.16 \mathrm{~mm}$ and $0.25 \mathrm{~mm}$. As a summary, the mid-span displacements and associated bearing movements observed on site are shown in the third and sixth columns of Table 4 .

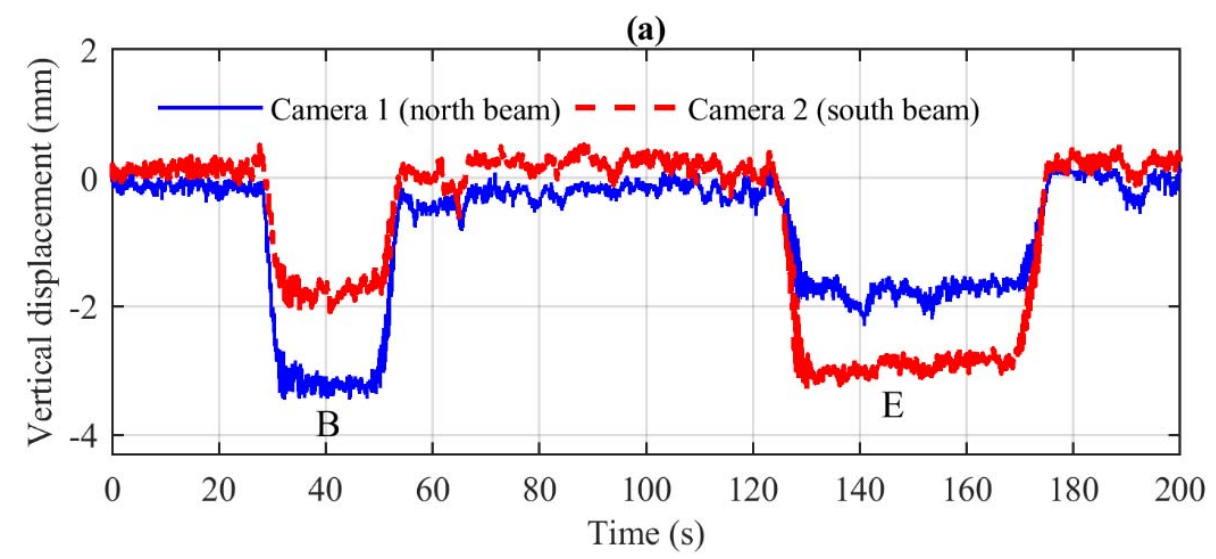

(b)

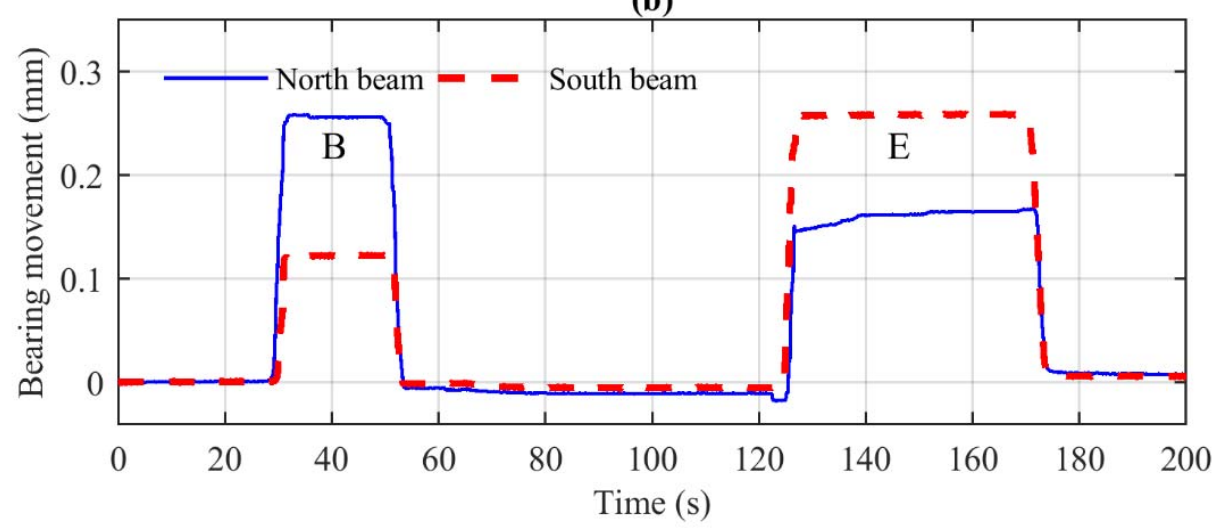

Fig 12, Mid-span and bearing displacements for test with unloaded truck, (a) mid-span displacement response (b) bearing movements.

\subsection{FE model updating following static test}

515 Having experimentally established the mid-span displacement and bearing displacement during a load test the next step was to see how well the FE models predicted this response. However, before discussing these results it is useful to recap on the FE models developed so far.

Model 0 is effectively the model that would be prepared from engineering drawings; it is a plate model which assumes pin-roller boundary conditions. Model 1 is an updated version of Model 0 in that it has a heavier mass of deck and it assumes pin-pin boundary conditions. Model 1 was found to be very accurate in capturing the dynamic behaviour of the deck.

From the bearing movements plotted in Fig. 12(b) it is obvious that under truck loading the applied loads are large enough that the deck no longer behaves as pinned-pinned, so using Model 1 directly would not be appropriate. Therefore to evaluate reliability of FEM predictions for the test with unloaded truck the two obvious options are: (i) to simulate the unloaded truck test using Model 0; or (ii) to use an amended form of Model 1 that has pin - roller boundary conditions. However, because 

above will give the same predictions for static load. Therefore it was decided to use Model 0 as this avoids the confusion of introducing an amended version of Model 1.

The Model 0 predictions for the mid-span and bearing displacements for stopping locations $B$ and $E$ for the unloaded truck are shown in columns four and seven of Table 4 (light shading). It can be seen that the Model 0 predictions significantly overestimate the actual displacements. This is most likely due to the fact that Model 0 takes no account of the frictional restraint imposed by bearing friction. Modern bearings use PTFE as the sliding material and friction coefficients in the region of 0.015-0.05 are expected [34]. From the drawings the bearings used in this bridge were from a company (Glacier Bearings) that at the time did not use pure PTFE, rather a material known as 'Glacier DU' was used as the sliding material. Precise specifications could not be obtained but correspondence with a representative of Technoslide revealed that the friction coefficient was likely to be slightly higher than in modern bearings i.e. probably in the region 0.03-0.06. (Technoslide is the current day company that evolved from Glacier Bearings). Finally it should be noted that the modelling in this section is attempting to simulate the restraint due to friction experienced by the bottom fibre of the beam, and from Figs. 12(b) it is evident that there is movement occurring in the bearing therefore strictly speaking we are simulating the dynamic friction coefficient. However, it is also important to bear in mind that the manufacturer of modern bridge bearings is such that the difference between static and dynamic friction coefficients is typically very small.

Having observed the restrained bearing behaviour in section 2.3, and established the range of friction coefficients likely to occur the next step was to simulate bearing friction in the FE model, then update the model (to get the best match for mid-span displacement) by updating parameter $\mu$, where $\mu$ is the friction coefficient of the bearings. The reason for getting the updated model to focus on mid-span displacements rather than bearing movements is that the bearing displacements are quite small and also show a certain amount of 'non-linearity/inelasticity' in the sense that they do not return exactly to zero when the truck leaves the bridge (see Fig. 12(b)). Admittedly the mid-span deck displacement plot in Fig. 12(a) also shows some non-linearity. However, on balance the deck displacement shows slightly less inelasticity than the bearing movement. Hence it was felt that a model optimised based on mid-span displacement measurements would be more robust than one optimised including bearing movements.

The base model for the updating was Model $0\left(E_{s}=206 \mathrm{GPa}\right.$ and $\left.E_{c}=30 \mathrm{GPa}\right)$ with assumed boundary conditions of pin-roller, and the only parameter to be updated was $\mu$. In this model, friction is simulated as a longitudinal (horizontal) force applied at the bottom fibre of the girder where the girder is supported on the roller bearing. The magnitude of this friction force is the product of the friction coefficient multiplied by the vertical force on the bearing. Where the vertical force on the bearing is approximately one quarter the weight of the bridge deck plus a portion of the weight of the truck.

The starting value of $\mu$ was taken as 0.025 , with upper and lower limits of 0.1 and 0.005 . Following a measurements, the value of $\mu$ converged to 0.0263 , which is within the range of expected values previously indicated. The progress of the updating process is presented in Fig. 13. Fig. 13(a) is the updated value of friction coefficient at each iteration step and the plot in figure $13(b)$ is the 

after 47 steps. This updated model is referred to as Model 2 and the predictions from Model 2 are shown in the $6^{\text {th }}$ and $11^{\text {th }}$ column of Table 4 (dark shading).

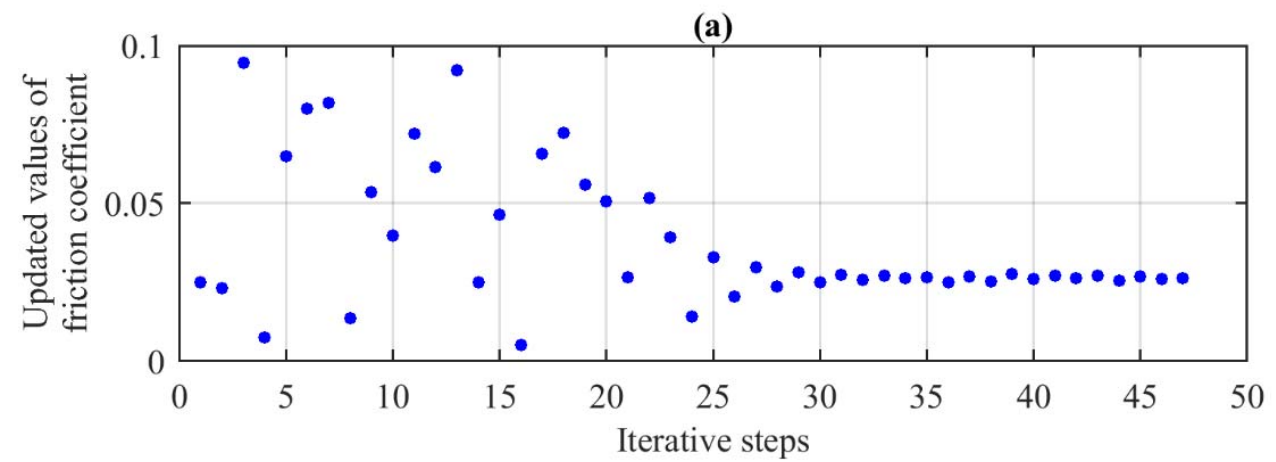

(b)

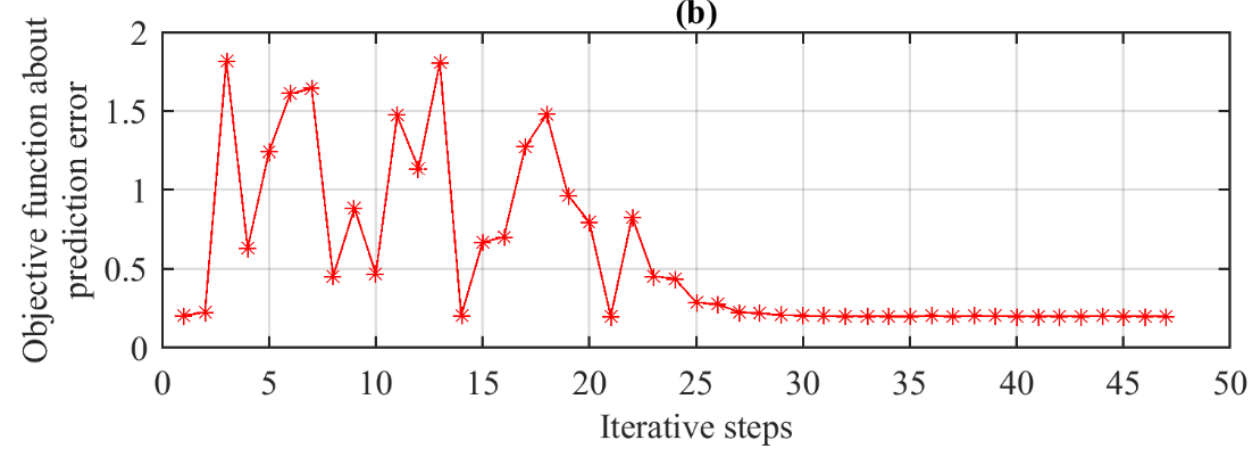

573

574

575

576

577

578

579

580

581

582

583

584

585

586

587

Fig. 13, Graphical overview of updating process, (a) updated values of friction coefficient for each iterative step (b) prediction error in the objective function for each friction coefficient shown in part (a).

The Model 2 predictions for the mid span displacements of the north and south beams match well with the measured values, which is to be expected as the model is optimised to match this, but the bearing movements are also reasonably well predicted by the model which builds confidence in the model. However, any FE model that has been updated using a limited amount of test data runs could give erroneous predictions in other loading scenarios. Therefore in the next section a more comprehensive load test was carried out using a loaded truck and the ability of Model 2 to predict the bridge response is examined.

Table 4, measured values of mid span displacement and bearing extension for test with unloaded truck compared to values predicted from base FE model (Model 0 ) and statically updated FE model (Model 2)

\begin{tabular}{|l|l|l|l|l|l|l|r|}
\hline & & \multicolumn{3}{|c|}{ Mid span deflection } & \multicolumn{3}{c|}{ Bearing movement } \\
\hline Beam & $\begin{array}{l}\text { Stop } \\
\text { position }\end{array}$ & $\begin{array}{l}\text { Field } \\
\text { test }\end{array}$ & Model 0 & Model 2 & $\begin{array}{l}\text { Field } \\
\text { test }\end{array}$ & Model 0 & Model 2 \\
\hline
\end{tabular}




\begin{tabular}{|l|l|l|l|l|l|l|l|l|l|l|l|}
\hline & & $(\mathrm{mm})$ & $(\mathrm{mm})$ & $\%$ diff & $(\mathrm{mm})$ & $\%$ diff & $(\mathrm{mm})$ & $(\mathrm{mm})$ & \% diff & $(\mathrm{mm})$ & \% diff \\
\hline North & B & 3.0 & 3.735 & 19.7 & 2.893 & -3.6 & 0.261 & 0.488 & -83.1 & 0.192 & -26.4 \\
\cline { 2 - 12 } & E & 1.72 & 2.327 & 26.1 & 1.49 & -13.4 & 0.162 & 0.384 & -74.2 & 0.091 & -43.8 \\
\hline South & B & 1.968 & 2.858 & 31.1 & 2.021 & 2.7 & 0.125 & 0.425 & -79.0 & 0.132 & 5.6 \\
\cline { 2 - 11 } & E & 3.121 & 4.266 & 26.8 & 3.421 & 9.6 & 0.258 & 0.527 & -84.6 & 0.231 & -10.5 \\
\hline
\end{tabular}

\section{$589 \quad 6.0$ Static test with loaded truck}

590 This test was carried out with the truck shown in Fig 10(a) but this time the truck was loaded so it 591 had a GVW of 32T rather than 12T which was the weight of the truck used in Section 5. Similar to the 592 test with unloaded truck we did not want there to be any other vehicle on the bridge other than the 593 test vehicle. Therefore the experimental campaign for the test with loaded truck was carried out 594 early in the morning in the hope that the road/bridge would be more or less free from other traffic 595 and this indeed proved to be the case which meant it was possible to stop the truck at all locations 596 A-F indicated in Fig. 11. The results for mid-span displacement and bearing movement are presented 597 in Sections 6.1.1 and 6.1.2 respectively.

\subsection{Experimental results of test with loaded truck}

\subsubsection{Mid span displacement}

600 Fig. 14 shows the mid-span displacement observed for 5 passes of the vehicle. In the first pass at 601 approximately 40 seconds the truck is travelling west and it does not stop on the bridge, this first pass was just to check that all the instruments were working properly before the static test. After the initial pass at 40 seconds the truck returns at approximately 140 seconds and it is travelling east. It stops consecutively at points A, B and C at approximately 140, 180 and 210 seconds, respectively, and the stopping locations are indicated on Fig. 14. It is clear that when the truck is travelling east (positions A-C) the north side beam shows larger displacement than the beam on the south side, this is simply because the truck is closer to the girder on the north side. The displacement when the truck is at point $A$ is smaller than when the truck is at point $C$ because the rear axles (which are heavier than the front axles) are closer to mid-span when the truck is at point $C$.

After crossing the bridge the truck turns around and returns travelling west, arriving at approximately 320 seconds. When the truck is travelling west (positions D-F) the beam on the south side shows the largest displacements because the truck is closer to the south girder. The largest displacement in the south girder $(\approx 10 \mathrm{~mm})$ occurs when the truck is at point $\mathrm{E}$. The corresponding displacement in in the north girder, when the truck is at location $B$, is slightly smaller ( $\approx 9 \mathrm{~mm})$. This is because the footpath on the south side is narrower and therefore when the truck is travelling west the truck is closer to the south girder than it is possible to get to the north girder when it is travelling east. Having stopped once at points A-F, the test is repeated and the truck stops at points A-F for a second time and the resulting bridge displacement is shown between 500 seconds and 750 seconds in Fig. 14. It can be seen that there is good repeatability between the first and second parts of the test. 


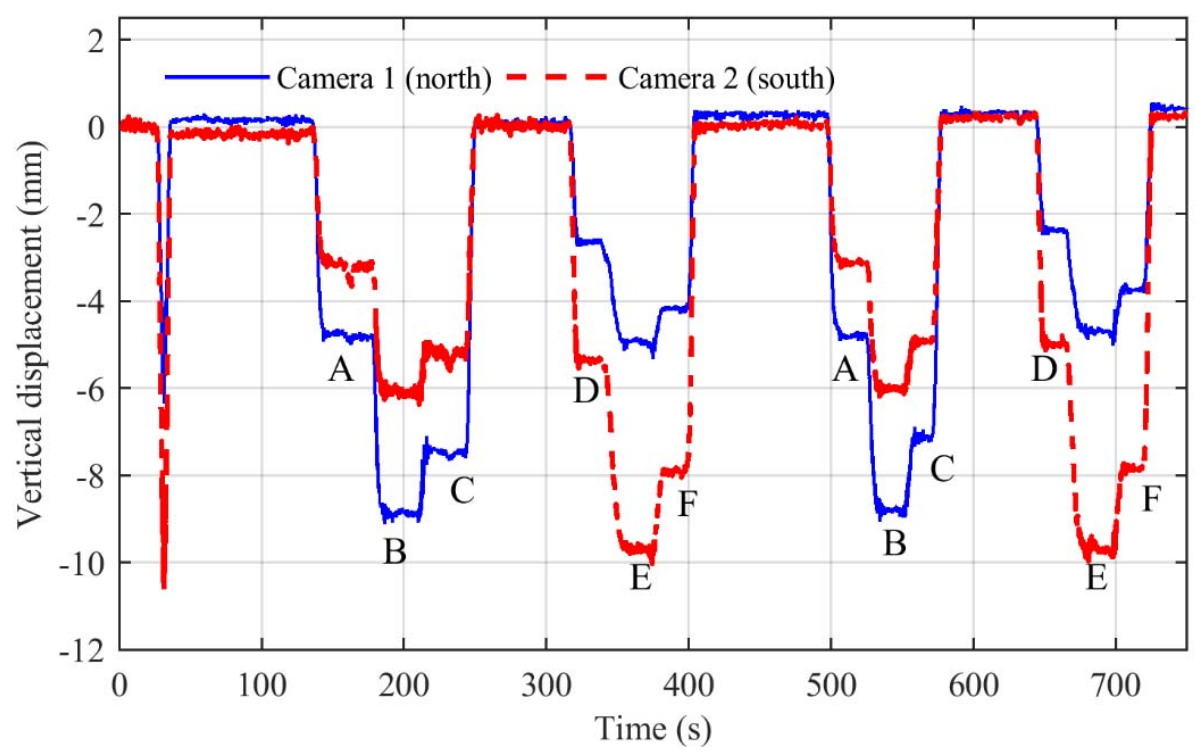

621

Fig. 14, Mid-span displacement for north and south girders for truck stopping locations A-F.

623

\section{$624 \quad 6.1 .2$ Bearing movement (LVDT)}

625 Fig. 15 shows the displacement observed at the 'roller' bearings at the east end of the deck and the 626 position of the truck A-F is also indicated. Similar to the pattern in Fig. 14 the girder closest to the truck experiences the largest displacement. The horizontal displacement when the truck is at quarter span (locations A \& D) is only approximately half the value when at mid-span or three quarter span. This is due to the fact that when the truck is at quarter span the heavier rear axles are close to the support. Interestingly when the truck leaves the bridge the beam does not relax to exactly the same horizontal position each time. Instead it has some residual positive and negative displacements depending on whether the truck is travelling east or west respectively. The exact cause of this behaviour is unknown, it may be that the bearing is exhibiting non-linear behaviour. Another possibility is that when the truck is travelling east the rear axles of the truck are immediately over the roller bearings as the truck is exiting the bridge. Consequently there is a sudden removal of load off the bearing which causes the bearing to release further, than when there is a more gradual removal of load (from the east side bearings) when the truck is travelling west. 


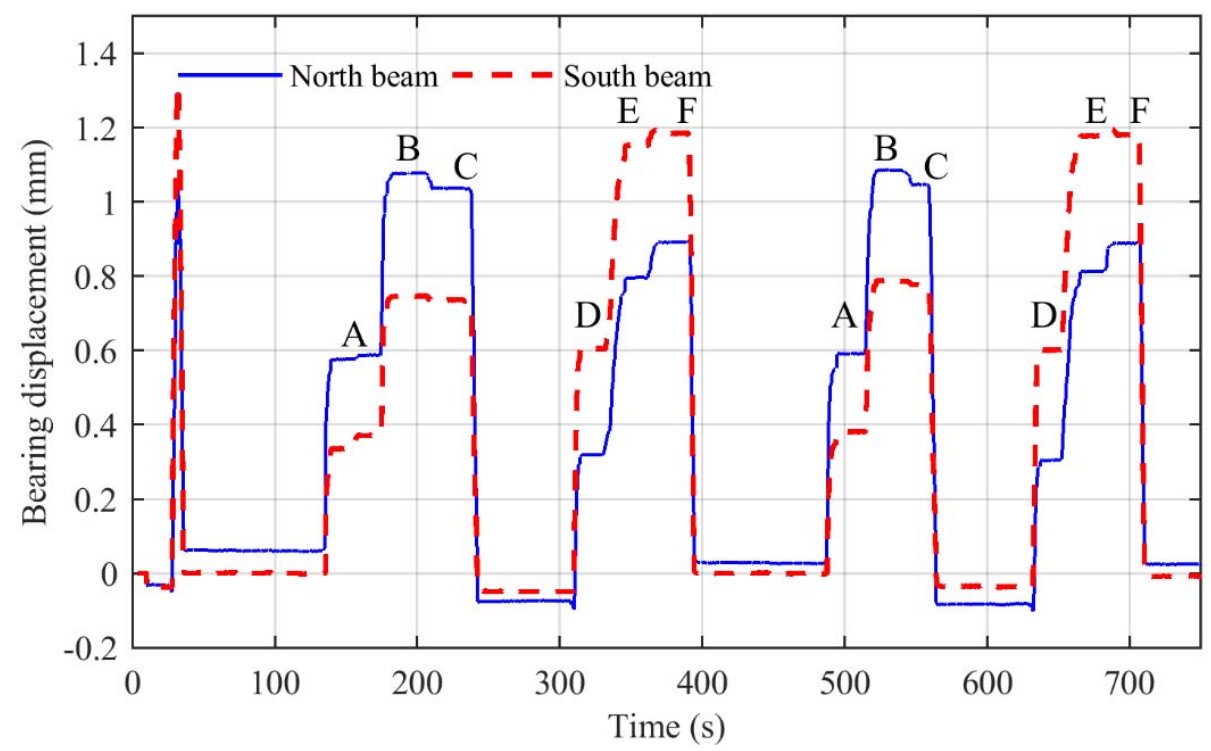

640 Fig 15, Movement of bottom fibre of the north and south girders on the east abutment.

641

\subsubsection{Summary table}

643 Table 5 shows the mid span deflections and bearing movements observed for the north and south 644 girders of the bridge for passes 1 and 2. It can be seen in the table that the measurements for pass 1 645 and 2 are very consistent so to avoid repetition in the next section where model predictions are 646 compared to measured results only the results of from pass 1 are presented.

647 Table 5, Summary of displacements observed at mid-span and at bearings during the load test.

\begin{tabular}{|c|c|c|c|c|c|c|c|c|}
\hline & \multicolumn{4}{|c|}{ North girder } & \multicolumn{4}{c|}{ South girder } \\
\hline & \multicolumn{2}{|c|}{$\begin{array}{c}\text { Mid-span } \\
\text { deflection }(\mathrm{mm})\end{array}$} & \multicolumn{2}{c|}{$\begin{array}{c}\text { Bearing } \\
\text { Deflection (mm) }\end{array}$} & \multicolumn{2}{c|}{$\begin{array}{c}\text { Mid-span } \\
\text { deflection }(\mathrm{mm})\end{array}$} & \multicolumn{2}{c|}{$\begin{array}{c}\text { Bearing } \\
\text { Deflection (mm) }\end{array}$} \\
\hline $\begin{array}{c}\text { Stop } \\
\text { position }\end{array}$ & $\begin{array}{c}\text { Pass 1 } \\
(\mathrm{mm})\end{array}$ & $\begin{array}{c}\text { Pass 2 } \\
(\mathrm{mm})\end{array}$ & $\begin{array}{c}\text { Pass 1 } \\
(\mathrm{mm})\end{array}$ & $\begin{array}{c}\text { Pass 2 } \\
(\mathrm{mm})\end{array}$ & $\begin{array}{c}\text { Pass 1 } \\
(\mathrm{mm})\end{array}$ & $\begin{array}{c}\text { Pass 2 } \\
(\mathrm{mm})\end{array}$ & $\begin{array}{c}\text { Pass 1 } \\
(\mathrm{mm})\end{array}$ & $\begin{array}{c}\text { Pass 2 } \\
(\mathrm{mm})\end{array}$ \\
\hline A & 4.874 & 5.089 & 0.583 & 0.619 & 3.027 & 3.247 & 0.360 & 0.398 \\
\hline B & 8.982 & 9.084 & 1.083 & 1.112 & 6.004 & 6.139 & 0.770 & 0.804 \\
\hline C & 7.610 & 7.419 & 1.044 & 1.075 & 5.181 & 5.064 & 0.759 & 0.794 \\
\hline D & 2.824 & 2.729 & 0.342 & 0.334 & 5.391 & 5.220 & 0.629 & 0.622 \\
\hline E & 5.106 & 5.049 & 0.819 & 0.842 & 9.703 & 9.925 & 1.178 & 1.199 \\
\hline F & 4.353 & 4.100 & 0.914 & 0.917 & 7.938 & 8.074 & 1.209 & 1.202 \\
\hline
\end{tabular}

651 For convenience the experimental data for mid-span displacement and bearing movement for Pass 1 shown in Table 5 is reproduced in columns 3 and 6 respectively of Table 6 . For comparison purposes the corresponding predictions of the base model (Model 0 ) for these loading scenarios are shown in columns 4 and 7 of Table 6 (light shading). It can be seen that similar to the test with unloaded truck, for most load positions Model 0 overestimates the displacement at both mid-span and at the 
bearing. Finally columns 5 and 8 of Table 6 (dark shading) show the Model 2 predictions for midspan displacement and bearing movement, where Model 2 is simply the FE model developed in Section 5.2. Here, Model 2 is checked against displacement from the test with the loaded truck so the friction coefficient is left at 0.0263 . It can be seen that for most load positions the mid-span displacements predicted by the Model 2 match well with those observed on site. The Model 2 predictions for bearing movements are not quite as accurate as are predictions for mid-span displacement but are still good and are significantly more accurate than the equivalent Model 0 predictions for bearing movement. The fact that Model 2 is slightly more accurate at predicting midspan displacement (than bearing movement) is not surprising considering that the updating described in section 5.2 was updated to for best fit to mid-span displacement rather than bearing movement.

Although the performance of Model 2 is very good for mid-span displacement, and certainly much more accurate than Model 0 , Model 2 is not perfect. For example for stop location $\mathrm{C}$, while the midspan displacement prediction for the south beam is very accurate (prediction: $5.098 \mathrm{~mm}$ Vs measured: $5.181 \mathrm{~mm}$ ) the prediction for the north beam underestimates the true displacement (prediction: $6.762 \mathrm{~mm}$ Vs measured: $7.610 \mathrm{~mm}$ ). Some inaccuracies in Model 2 predictions for stop location C (and/or locations A, D \& F) are not totally surprising when considering that Model 2 was only updated using the mid-span displacement for load positions $B$ and $E$ in the test with the unloaded truck. In fact this demonstrates one of the fundamental challenges of model updating, i.e. that while a FE model might show excellent predictions for the set of data it was updated on there is no guarantee that it will be as accurate when used to predict the bridge response to a different loading scenario. Hence the importance of having data from more than one measurement campaign, so that the robustness of an updated FE model can be accessed.

Finally it should be noted that this study is not an attempt to get a perfect model, rather to demonstrate that with limited field measurements, particularly including some boundary conditions measurements, it is possible to use relatively simple updating procedures to achieve a FE model whose predictions provide an appreciably better match with experimentally observed values than the predictions of an updated model.

Table 6, Measured, Model 0 and Model 2 predictions for stopping locations A-F with loaded truck

\begin{tabular}{|c|c|c|c|c|c|c|c|c|c|c|c|}
\hline \multirow{3}{*}{ Beam } & \multirow{3}{*}{$\begin{array}{l}\text { Stop } \\
\text { Position }\end{array}$} & \multicolumn{5}{|c|}{ Mid span deflection } & \multicolumn{5}{|c|}{ Bearing movement } \\
\hline & & \multirow{2}{*}{$\begin{array}{l}\text { Field } \\
\text { test }\end{array}$} & \multicolumn{2}{|c|}{ Model 0} & \multicolumn{2}{|c|}{ Model 2} & \multirow{2}{*}{$\begin{array}{l}\text { Field } \\
\text { test }\end{array}$} & \multicolumn{2}{|c|}{ Model 0} & \multicolumn{2}{|c|}{ Model 2} \\
\hline & & & $(\mathrm{mm})$ & \% diff & $(\mathrm{mm})$ & $\%$ diff & & $(\mathrm{mm})$ & \% diff & $(\mathrm{mm})$ & $\%$ diff \\
\hline \multirow[b]{3}{*}{ North } & A & 4.874 & 5.782 & 15.7 & 4.972 & 2.0 & 0.583 & 0.837 & -83.2 & 0.553 & -5.1 \\
\hline & B & 8.982 & 9.885 & 9.1 & 8.995 & 0.1 & 1.083 & 1.289 & -85.7 & 0.977 & -9.8 \\
\hline & C & 7.610 & 7.651 & 0.5 & 6.762 & -11.1 & 1.044 & 1.083 & -84.0 & 0.771 & -26.1 \\
\hline
\end{tabular}




\begin{tabular}{|l|l|l|l|l|l|l|l|l|l|l|l|}
\hline \multirow{5}{*}{} & D & 2.824 & 3.473 & 18.7 & 2.555 & -9.5 & 0.342 & 0.623 & -75.6 & 0.302 & -11.7 \\
\cline { 2 - 11 } & E & 5.106 & 6.040 & 15.5 & 5.153 & 0.9 & 0.819 & 1.003 & -80.5 & 0.693 & -15.4 \\
\cline { 2 - 11 } & F & 4.353 & 5.041 & 13.6 & 4.188 & -3.8 & 0.914 & 0.889 & -78.8 & 0.59 & -35.4 \\
\hline \multirow{5}{*}{ South } & A & 3.027 & 4.538 & 33.3 & 3.728 & 23.2 & 0.360 & 0.762 & -79.6 & 0.478 & 32.8 \\
\cline { 2 - 11 } & B & 6.004 & 7.460 & 19.5 & 6.58 & 9.6 & 0.770 & 1.121 & -83.0 & 0.813 & 5.6 \\
\cline { 2 - 11 } & D & 5.181 & 5.977 & 13.3 & 5.098 & -1.6 & 0.759 & 0.925 & -81.9 & 0.617 & -18.7 \\
\cline { 2 - 11 } & E & 5.391 & 6.845 & 21.2 & 5.887 & 9.2 & 0.629 & 0.976 & -83.4 & 0.639 & 1.6 \\
\cline { 2 - 11 } & F & 7.938 & 8.584 & 7.5 & 7.723 & -2.7 & 1.209 & 1.115 & -85.6 & 0.813 & -32.8 \\
\hline
\end{tabular}

687

688

\section{9}

690

691

692

693

694

695

696

697

698

699

700

701

702

703

704

705

706

707

708

709

710

711

712

713

714

\subsection{Conclusions}

This paper presents the results of model updating with particular attention to bearing movements which are often not appropriately accounted for during the conceptualisation of a bridge using numerical models. Before discussing the findings of including the effect of bearings in the FE model it is import to point out that the bearings are not the only factor to be considered when conceptualising the physical model (e.g. the effect of bitumen surfacing) it is just that the effect of bearings is the focus of this paper. Typically, the bearings are conventionally idealised pin-roller supports, which often does not represent their true behaviour and hence leads to inaccuracies in the model. The significance of bearing' movement has been scarcely tested against real-life experimental data due to the difficulties associated with obtaining the data on bearing' behaviour on site. With this in mind it was shown that to get the dynamic model (Model 1) to generate the correct modal frequencies it was very important to have been able to identify that under light weight ambient traffic the bridge bearings were in effect behaving as 'pin-pin'. Otherwise in the updating procedure, the system parameters (e.g. Youngs modulus, deck mass) would have been driven to unrealistic values in order to get the FE predictions to match the experimentally observed frequencies. However, it should be noted that while the parameter value obtained post updating appears credible, and this is positive and helps give confidence to the model, the risk that an incomplete model is being compensated by a biased parameter value cannot be completely discounted. The bearing restraint evident in the dynamic test was assumed to be due to friction in the bearings. This field observation about bearing friction was exploited in the static model (Model 2) where friction was implemented in the bearings leading to static predictions that better matched the experimentally observed values than the predictions of the base model (Model 0 ) which assumes 'pin-roller' boundary conditions. As well as demonstrating the useful modelling information that can be gathered by taking field measurements on the bearings, this paper also demonstrates the importance of having data from multiple tests when carrying out model updating as this allows the robustness of the updated model to be accessed. However, even with results from multiple tests it 
cannot be guaranteed that that the updated model can be used to accurately extrapolate/predict bridge response outside the range observed during testing.

\section{Acknowledgements}

The research leading to these results has received funding from the People Programme (Marie Curie Actions) of the European Union's Seventh Framework Programme (FP7/2007-2013) under grant agreement $n^{\circ} 330195$. The authors would also like to acknowledge the Bridge Section of The Engineering Design Group of Devon County Council led by Kevin Dentith BSc, CEng, FICE, for their support and assistance with this work. Mike Roseblade of Technoslide also kindly helped us with the historical information on the bearings.

\section{References}

[1] R. N. Merce, G. N. Doz, J. H. G. Macdonald, and M. I. Friswell, 'FINITE ELEMENT MODEL UPDATING OF A SUSPENSION BRIDGE USING ANSYS SOFTWARE', in Inverse Problems, 2007, p. 8.

[2] S. A. Kilic, H. J. Raatschen, B. Körfgen, N. M. Apaydin, and A. Astaneh-Asl, 'FE Model of the Fatih Sultan Mehmet Suspension Bridge Using Thin Shell Finite Elements', Arab. J. Sci. Eng., vol. 42, no. 3, pp. 1103-1116, Mar. 2017.

[3] Brownjohn James M. W. and Xia Pin-Qi, 'Dynamic Assessment of Curved Cable-Stayed Bridge by Model Updating', J. Struct. Eng., vol. 126, no. 2, pp. 252-260, Feb. 2000.

[4] W. Park, J. Park, and H.-K. Kim, 'Candidate model construction of a cable-stayed bridge using parameterised sensitivity-based finite element model updating', Struct. Infrastruct. Eng., vol. 11, no. 9, pp. 1163-1177, Sep. 2015.

[5] A. Bayraktar, A. C. Altunisik, B. Sevim, and T. Turker, 'Finite element model updating of Kömürhan highway bridge based on experimental measurements', Smart Struct. Syst., vol. 6, no. 4, pp. 373-388, May 2010.

[6] X. Lin, L. Zhang, Q. Guo, and Y. Zhang, 'Dynamic finite element model updating of prestressed concrete continuous box-girder bridge', Earthq. Eng. Eng. Vib., vol. 8, no. 3, pp. 399-407, Sep. 2009.

[7] A. Bayraktar, F. Birinci, A. C. Altunışık, T. Türker, and B. Sevim, 'Finite Element Model Updating of Senyuva Historical Arch Bridge Using Ambient Vibration Tests', Balt. J. Road Bridge Eng., vol. 4, no. 4, pp. 177-185, Dec. 2009.

[8] B. Jaishi, H.-J. Kim, M. K. Kim, W.-X. Ren, and S.-H. Lee, 'Finite element model updating of concrete-filled steel tubular arch bridge under operational condition using modal flexibility', Mech. Syst. Signal Process., vol. 21, no. 6, pp. 2406-2426, Aug. 2007.

[9] H. Ahmadian, J. E. Mottershead, and M. I. Friswell, 'REGULARISATION METHODS FOR FINITE ELEMENT MODEL UPDATING', Mech. Syst. Signal Process., vol. 12, no. 1, pp. 47-64, Jan. 1998.

[10] H.-P. Chen and T.-L. Huang, 'Updating finite element model using dynamic perturbation method and regularization algorithm', Smart Struct. Syst., vol. 10, no. 4_5, pp. 427-442, Oct. 2012.

[11] D.-S. Jung and C.-Y. Kim, 'Finite element model updating on small-scale bridge model using the hybrid genetic algorithm', Struct. Infrastruct. Eng., vol. 9, no. 5, pp. 481-495, May 2013. 
[12] M. Sanayei, A. Khaloo, M. Gul, and F. Necati Catbas, 'Automated finite element model updating of a scale bridge model using measured static and modal test data', Eng. Struct., vol. 102, pp. 66-79, Nov. 2015.

[13] H. Schlune, M. Plos, and K. Gylltoft, 'Improved bridge evaluation through finite element model updating using static and dynamic measurements', Eng. Struct., vol. 31, no. 7, pp. 1477-1485, Jul. 2009.

[14] H. Wang, A. Li, and J. Li, 'Progressive finite element model calibration of a long-span suspension bridge based on ambient vibration and static measurements', Eng. Struct., vol. 32, no. 9, pp. 2546-2556, Sep. 2010.

[15] J. M. W. Brownjohn, P. Moyo, P. Omenzetter, and Y. Lu, 'Assessment of Highway Bridge Upgrading by Dynamic Testing and Finite-Element Model Updating', J. Bridge Eng., vol. 8, no. 3, pp. 162-172, May 2003.

[16] Y. Ding and A. Li, 'Finite Element Model Updating for the Runyang Cable-Stayed Bridge Tower Using Ambient Vibration Test Results', Adv. Struct. Eng., vol. 11, no. 3, pp. 323-335, Jun. 2008.

[17] M. Sanayei, B. Arya, E. M. Santini, and S. Wadia-Fascetti, 'Significance of Modeling Error in Structural Parameter Estimation', Comput.-Aided Civ. Infrastruct. Eng., vol. 16, no. 1, pp. $12-$ 27, Jan. 2001.

[18] J. D. Sipple and M. Sanayei, 'Full-Scale Bridge Finite-Element Model Calibration Using Measured Frequency-Response Functions', J. Bridge Eng., vol. 20, no. 9, p. 04014103, Sep. 2015.

[19] N. R. Polanco, G. May, and E. M. Hernandez, 'Finite element model updating of semi-composite bridge decks using operational acceleration measurements', Eng. Struct., vol. 126, pp. 264277, Nov. 2016.

[20] J.-A. Goulet, P. Kripakaran, and I. F. C. Smith, 'Multimodel Structural Performance Monitoring', J. Struct. Eng., vol. 136, no. 10, pp. 1309-1318, Oct. 2010.

[21] J.-A. Goulet, C. Michel, and I. F. C. Smith, 'Hybrid probabilities and error-domain structural identification using ambient vibration monitoring', Mech. Syst. Signal Process., vol. 37, no. 1, pp. 199-212, May 2013.

[22] J. A. Goulet and I. F. C. Smith, 'Predicting the Usefulness of Monitoring for Identifying the Behavior of Structures', J. Struct. Eng., vol. 139, no. 10, pp. 1716-1727, Oct. 2013.

[23] J.-A. Goulet, M. Texier, C. Michel, I. F. C. Smith, and L. Chouinard, 'Quantifying the Effects of Modeling Simplifications for Structural Identification of Bridges', J. Bridge Eng., vol. 19, no. 1, pp. 59-71, Jan. 2014.

[24] J.-A. Goulet and I. F. C. Smith, 'Structural identification with systematic errors and unknown uncertainty dependencies', Comput. Struct., vol. 128, pp. 251-258, Nov. 2013.

[25] J. Brynjarsdottir and A. O'Hagen, 'Learning about physical parameters: The importance of Model discrepancy', Inverse Problems, vol. 30, no. 11, 2014.

[26] D. Hester, J. Brownjohn, M. Bocian, Y. Xu, and A. Quattrone, 'Using inertial measurement units originally developed for biomechanics for modal testing of civil engineering structures', Mech. Syst. Signal Process., vol. 104, pp. 776-798, May 2018.

[27] J. M. Caicedo, 'PRACTICAL GUIDELINES FOR THE NATURAL EXCITATION TECHNIQUE (NEXT) AND THE EIGENSYSTEM REALIZATION ALGORITHM (ERA) FOR MODAL IDENTIFICATION USING AMBIENT VIBRATION', Exp. Tech., vol. 35, no. 4, pp. 52-58, Jul. 2011.

[28] C. Gentile and N. Gallino, 'Ambient vibration testing and structural evaluation of an historic suspension footbridge', Adv. Eng. Softw., vol. 39, no. 4, pp. 356-366, Apr. 2008.

[29] K. Van Nimmen et al., 'Numerical and experimental analysis of the vibration serviceability of the Bears' Cage footbridge', Struct. Infrastruct. Eng., vol. 13, no. 3, pp. 390-400, Mar. 2017.

[30] Siu-Kui Au, Operational Modal Analysis - Modeling, Bayesian Inference, Uncertainty Laws. Springer. 
807

808

809

810

811

812

813

814

815

816
[31] J. M. W. Brownjohn, H. Hong, and P. T. Chien, 'ASSESSMENT OF STRUCTURAL CONDITION OF BRIDGES BY DYNAMIC MEASUREMENTS', p. 56.

[32] S.P. Timoshenko, J.M. Gere, 'Mechanics of Materials: fourth SI edition', Stanley Thomas, 1999, ISBN $074873995 \mathrm{X}$

[33] Audet, Charles, and J. E. Dennis Jr. 'Analysis of Generalized Pattern Searches'. SIAM Journal on Optimization. vol. 13, no. 3,pp. 889-903, 2003.

[34] Technoslide-Civil Bearings-Pot Bearings, Friction coefficient, \{ http://www.technoslide.com/potbearings.html\} 